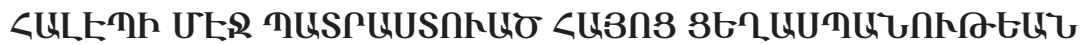

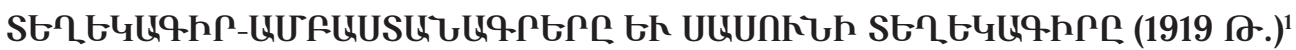

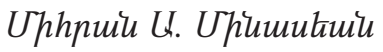

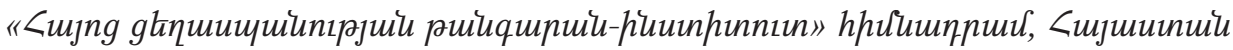

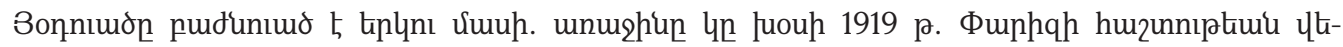

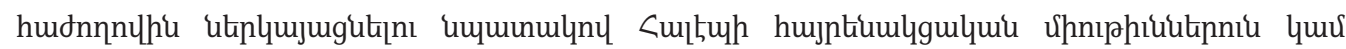

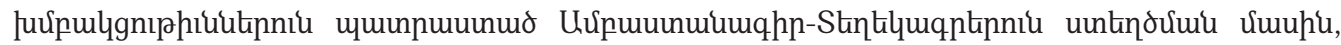

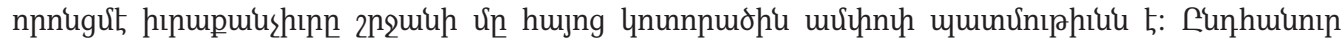

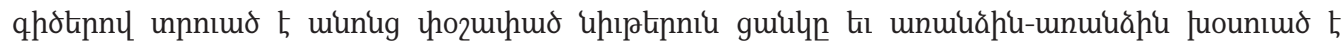

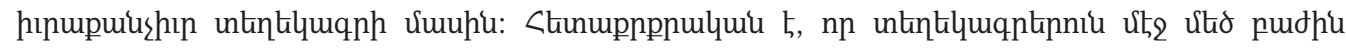

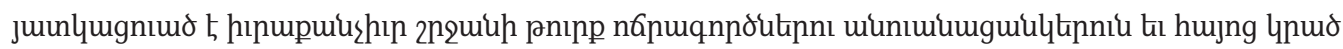
upıpulumu lnpniuunutinniu:

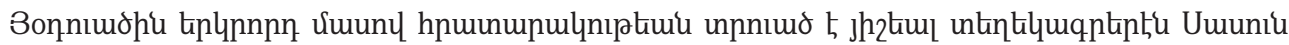

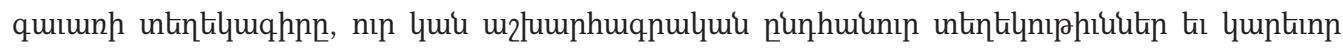

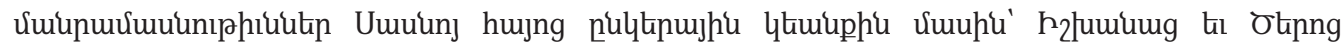

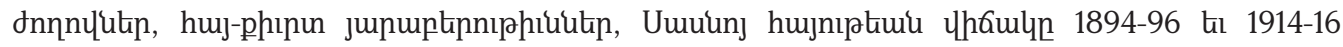

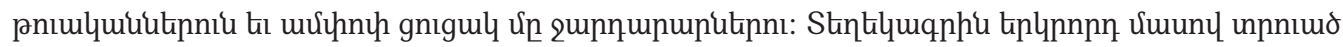

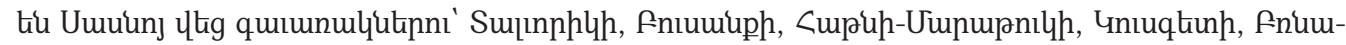

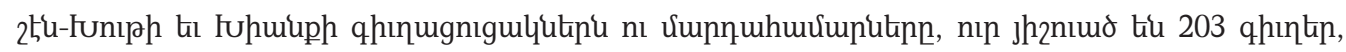

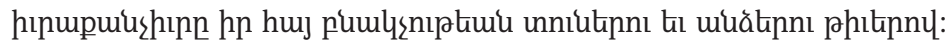

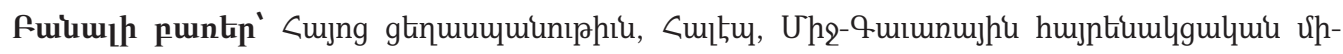

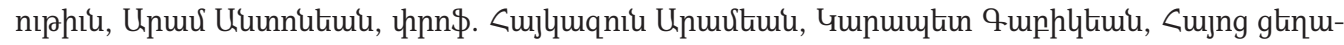

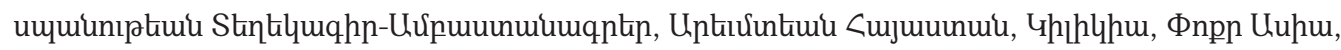

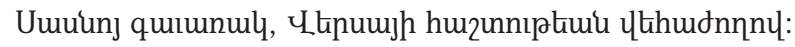

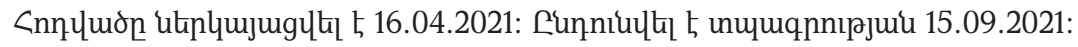

The article was submitted on 16.04.2021 and accepted for publication on 15.09.2021.

Статья поступила 16.04.2021 и была принята к публикации 15.09.2021.

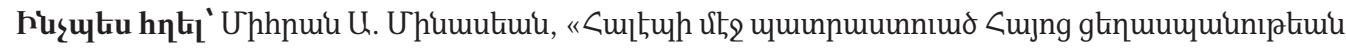

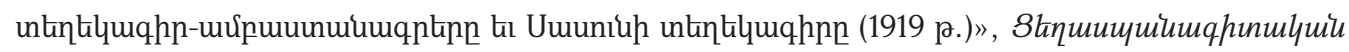
huiuqku 9, no. 2 (2021), 93-126:

How to cite: Mihran A. Minassian, "The Indictment Documents on the Armenian Genocide Written in Aleppo and the Sassoun Document (1919)," Ts'eghaspanagitakan handes 9, no. 1 (2021): 93-126.

Как ссылаться: Мигран А. Минасян, “Созданные в Алеппо обвинительные справочники Геноцида армян и справочник Сасуна (1919 г.),” Тсехаспанагитакан андес 9, по. 1 (2021): 93-126.

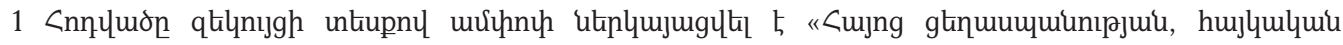

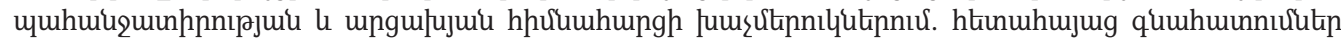

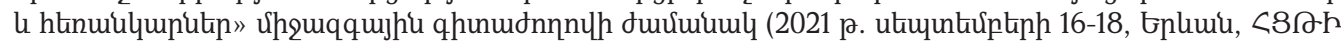

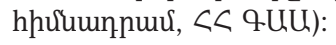




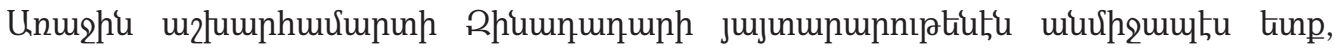

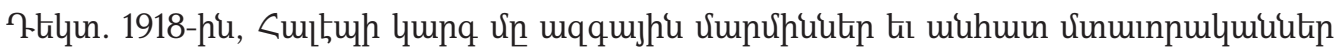

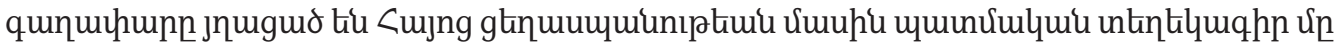

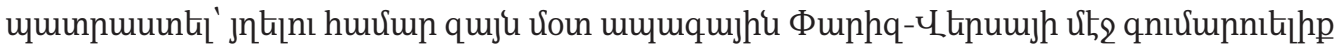

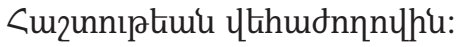

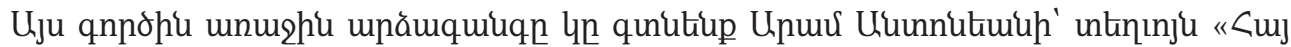

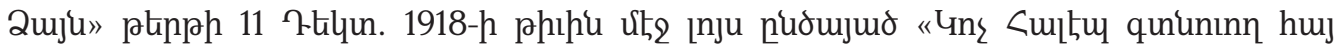

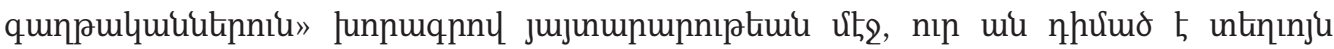

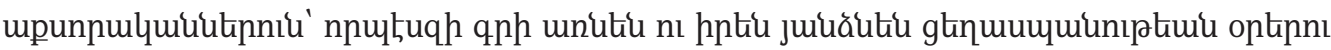

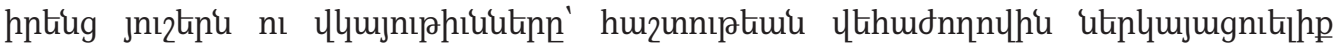

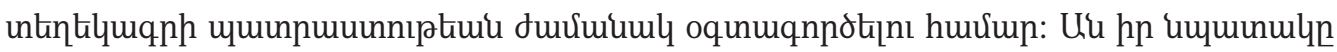

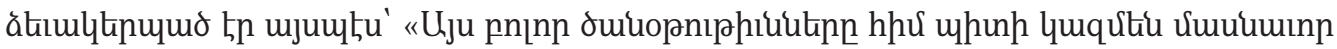

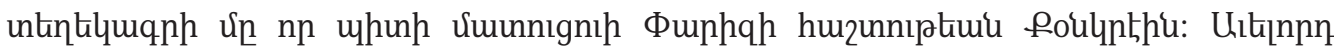

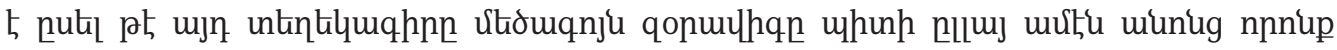

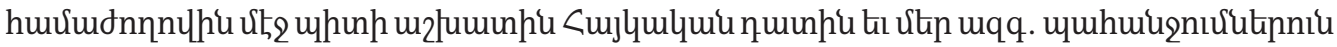
jųnnnıptimu» ${ }^{2}$ :

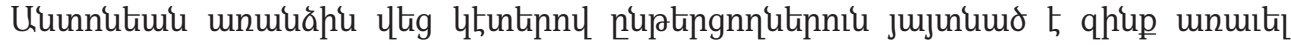

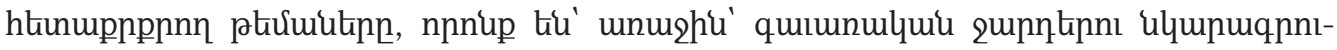

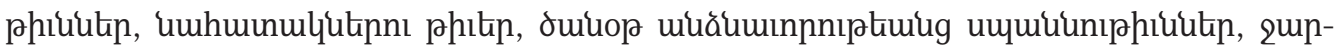

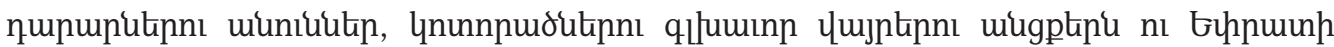

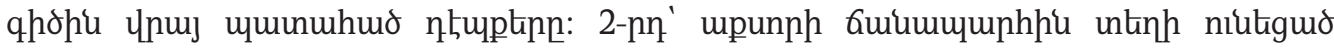

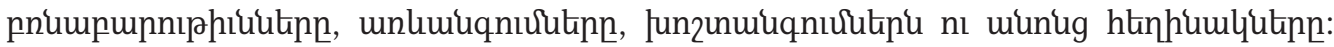

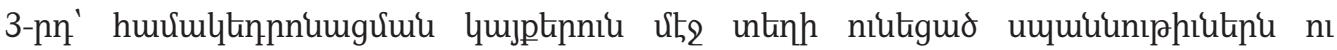

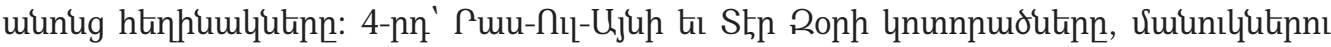

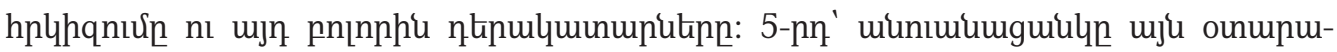

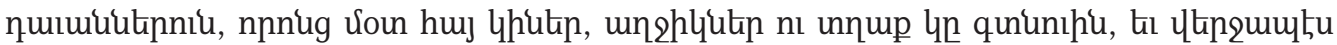

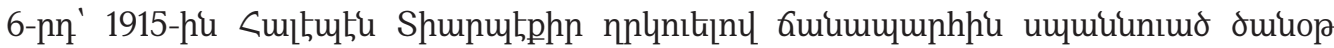

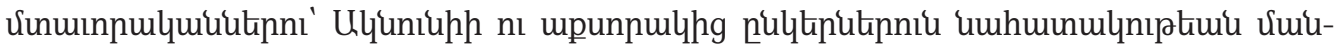

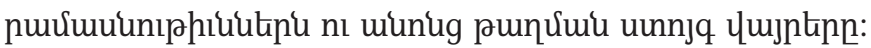

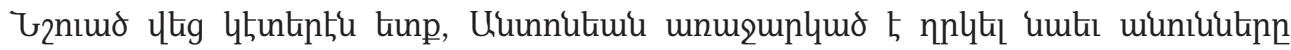

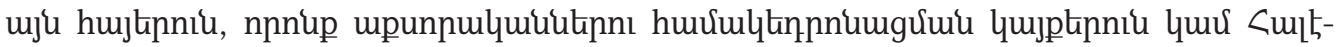

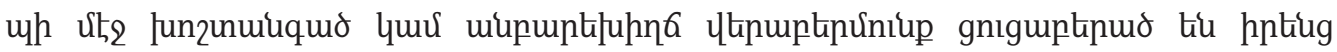
mqqulhghutinniu ulquinumunp:

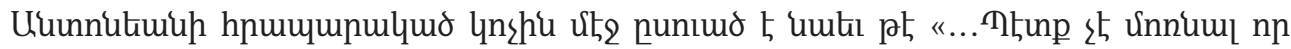

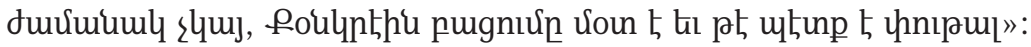

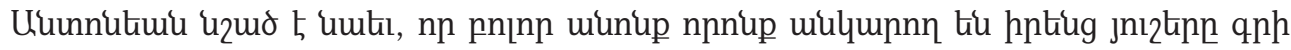

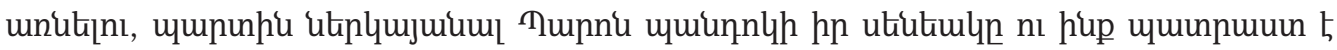

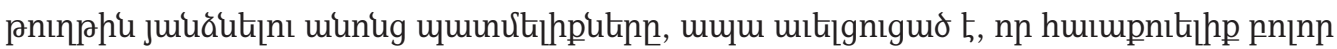

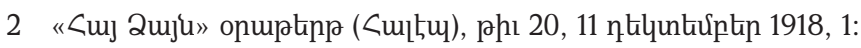




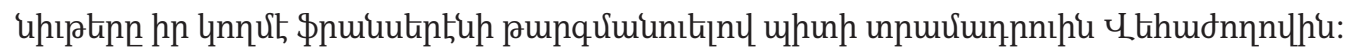

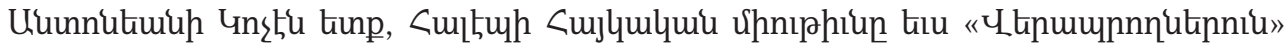

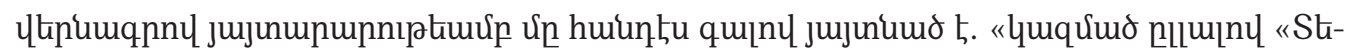

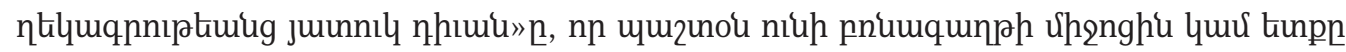

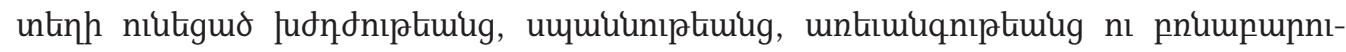

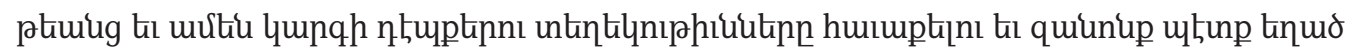

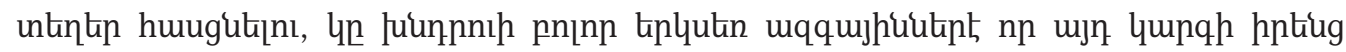

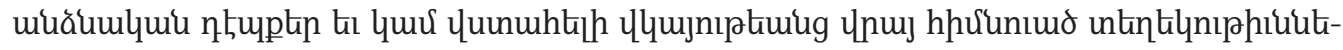

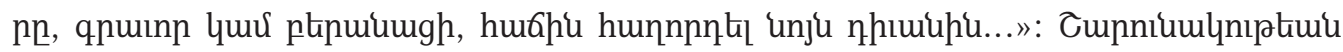

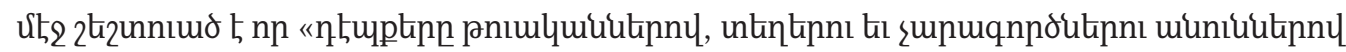

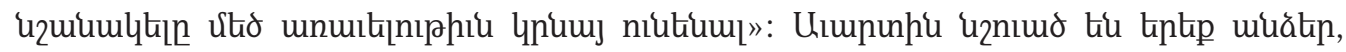

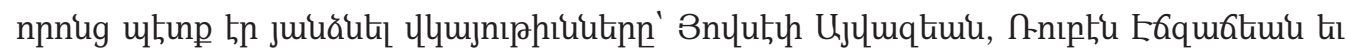
po. [fumshly] Tonnutiuü:

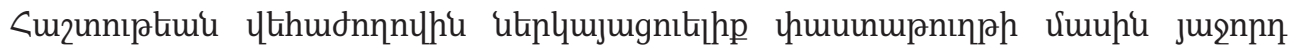

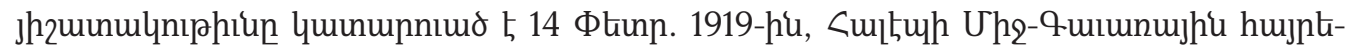

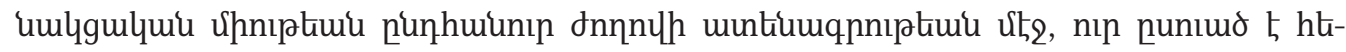

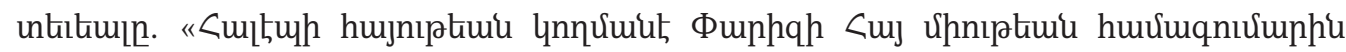

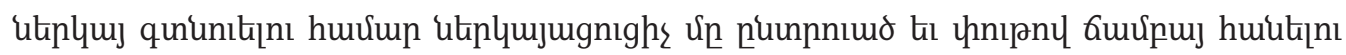

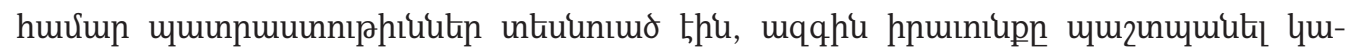

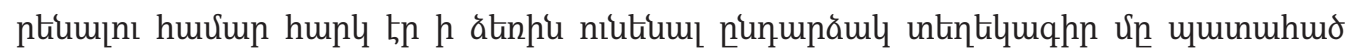

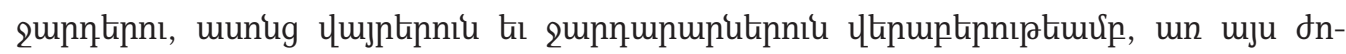

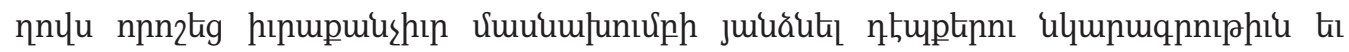

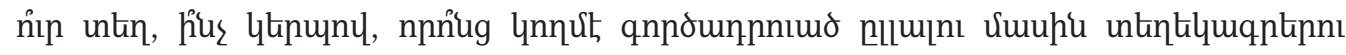

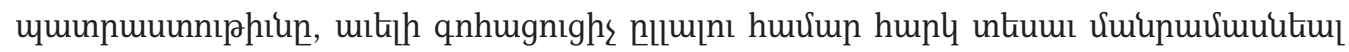

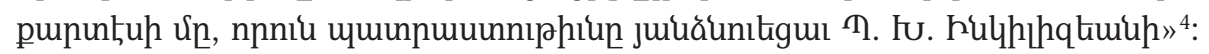

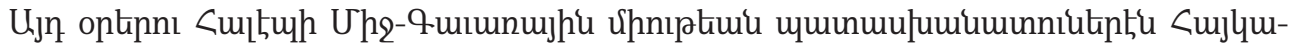

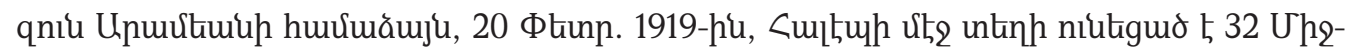

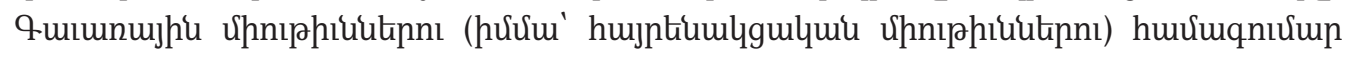

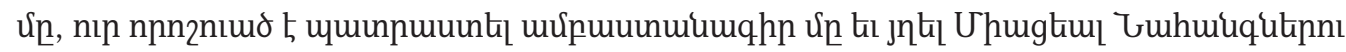

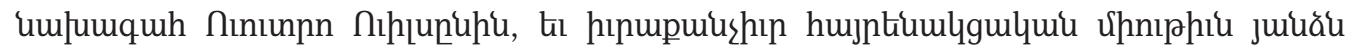

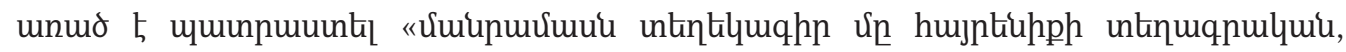

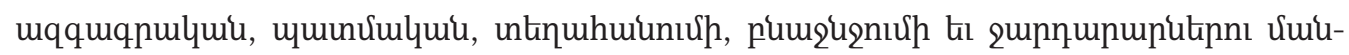
nuर्umui untinhphiknny»

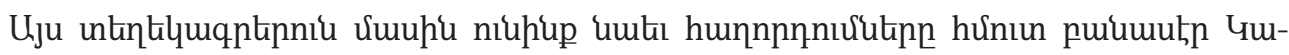

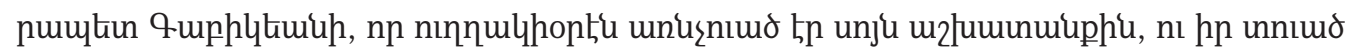

3 «டuj 2uju», phi 52, 12 jniuniup 1919, 3:

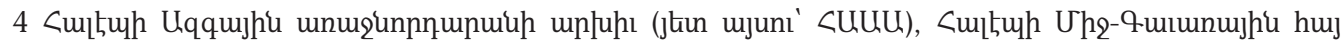

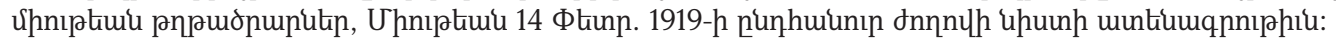

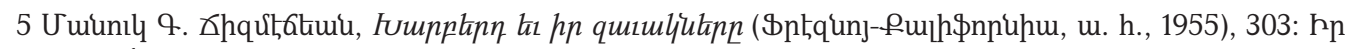

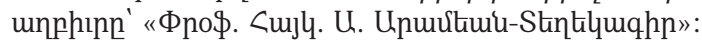




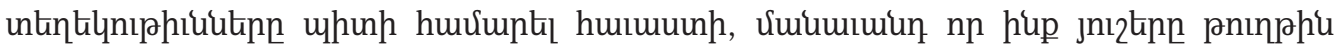

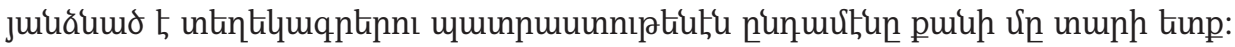

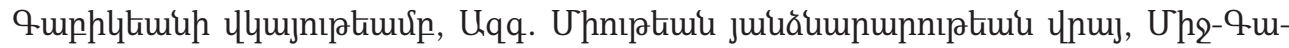

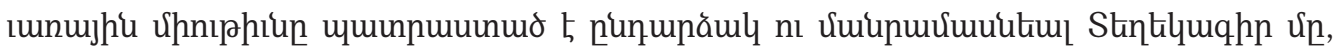

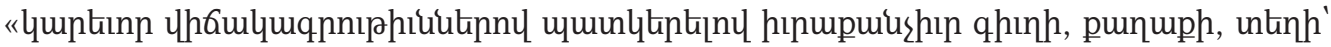

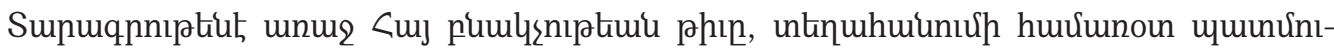

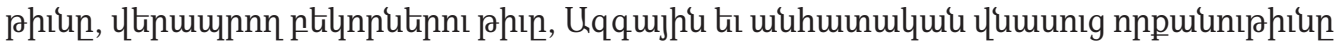

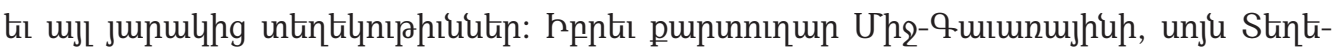

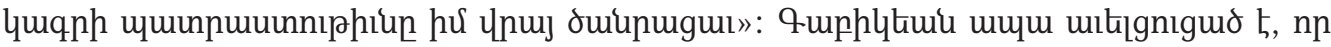

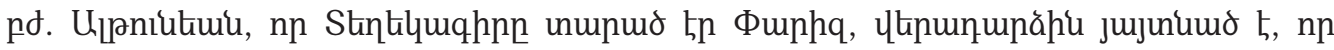

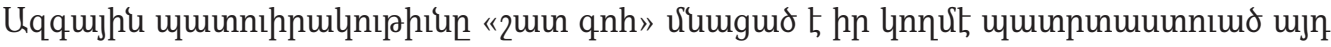
Stintilumqntít

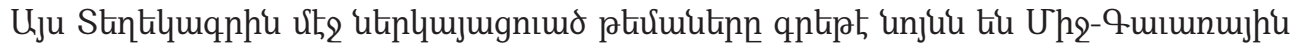

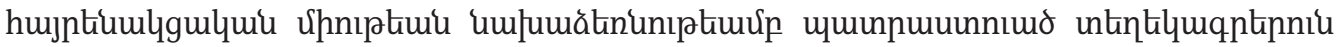

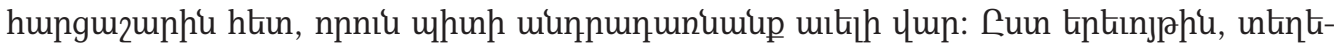

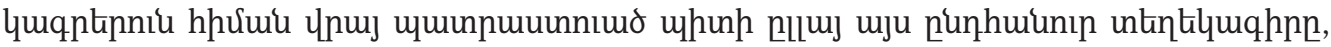

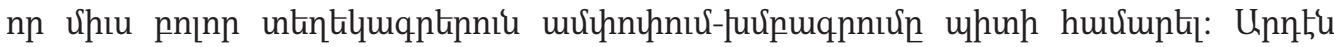

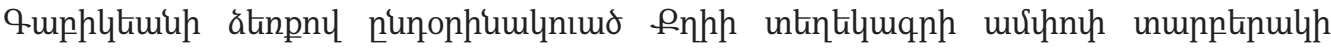

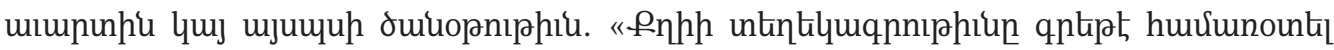

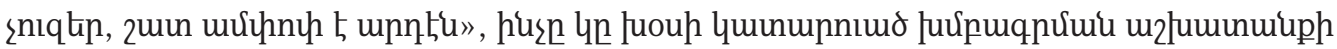
un Umuni:

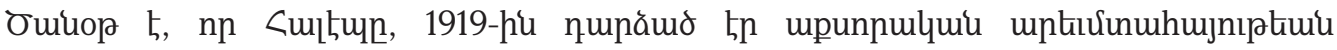

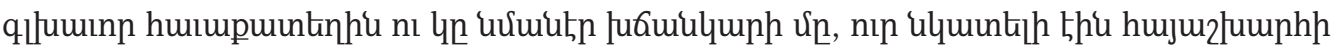

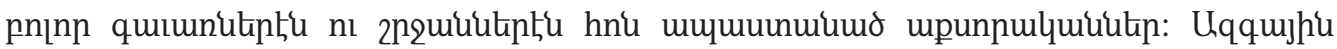

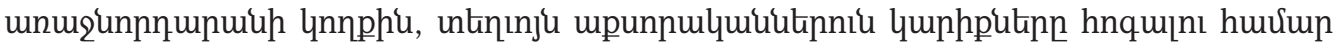

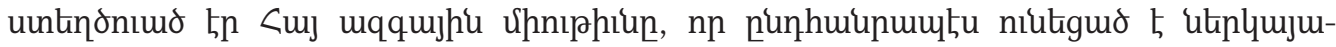

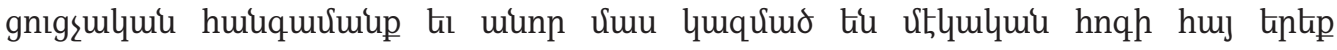

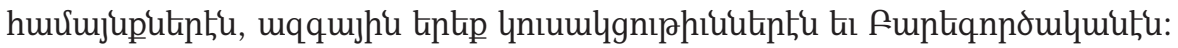

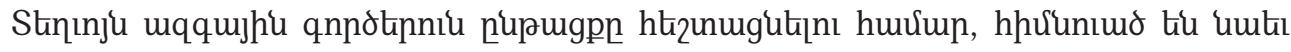

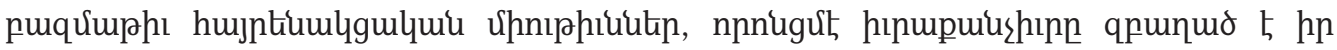

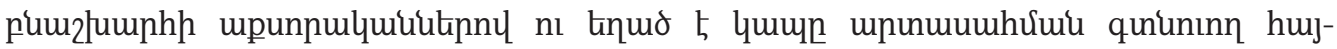

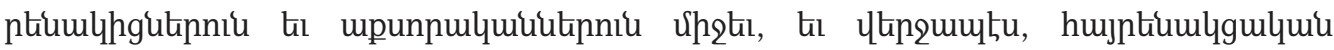

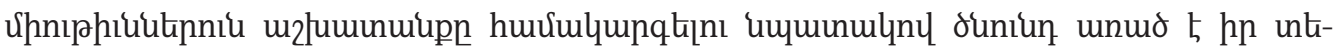

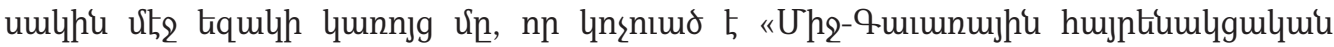

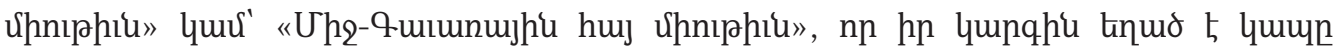

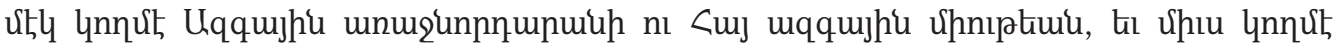

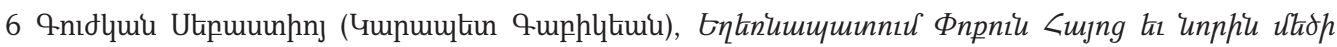

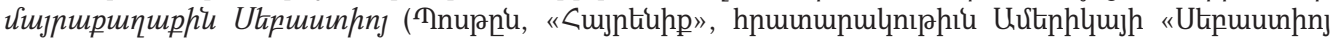
utinurhunıptuiu uhnıtiui», 1924), 550: 


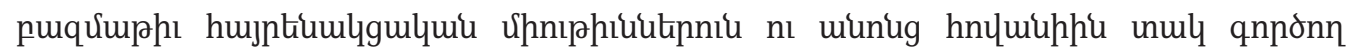
Uumumuluniupkinniu:

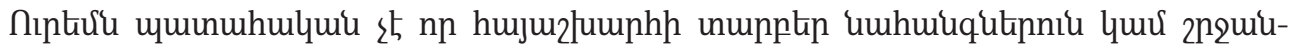

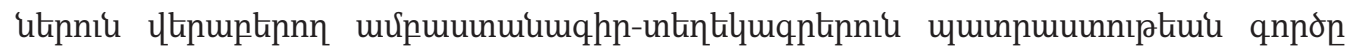

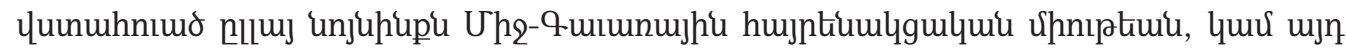

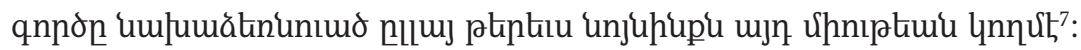

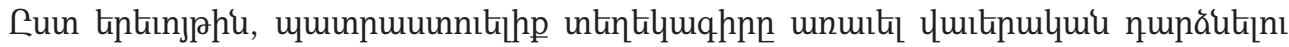

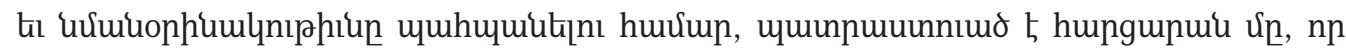

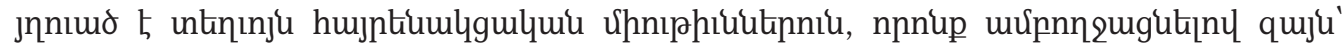

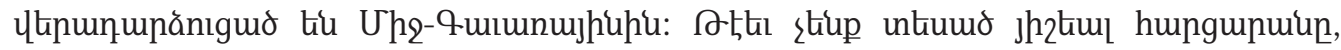

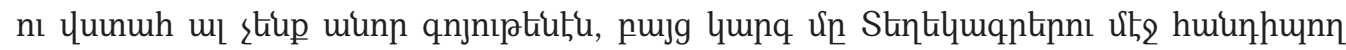

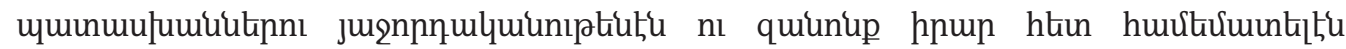

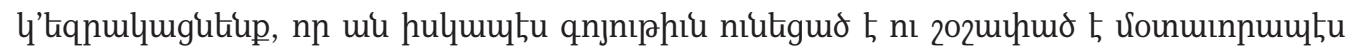
hkunkituml hunghinn.

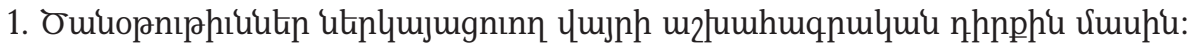

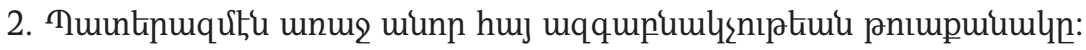

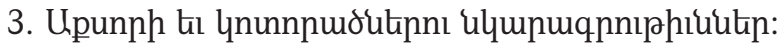

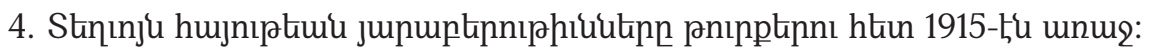

5. 1915-h umburnulyutpnitu Uounuinn phıр:

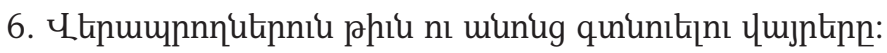

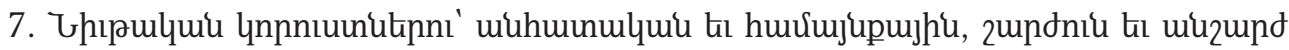

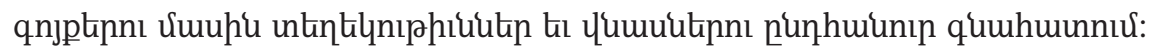

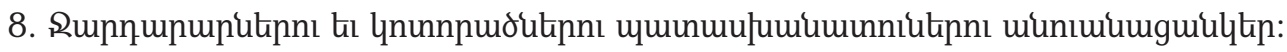

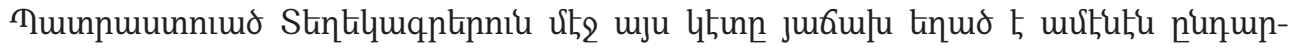

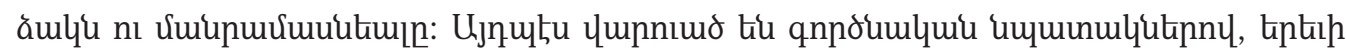

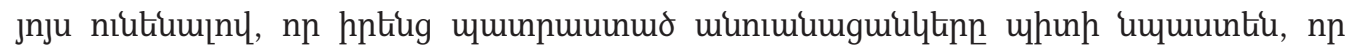

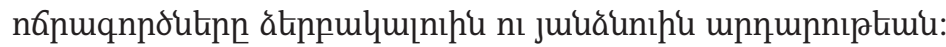

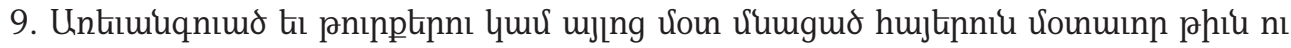
munug munimumguilitin:

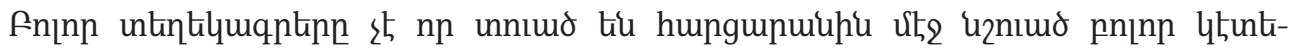

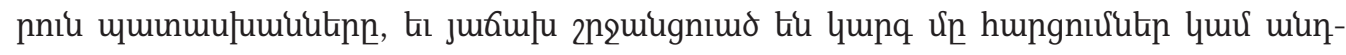

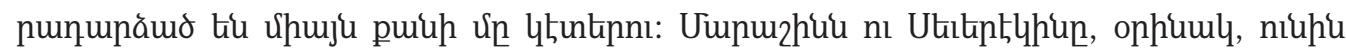

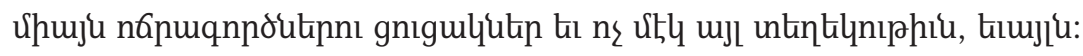

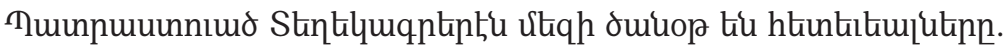

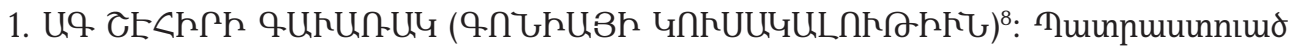
5 23 Фtinn. 1919-hu, 8 5,2:

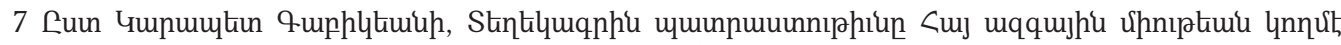

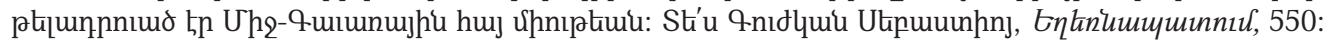

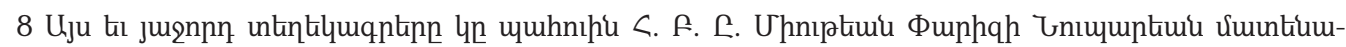

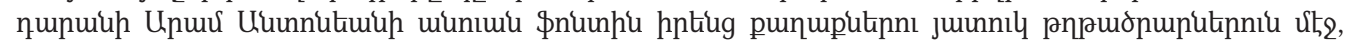




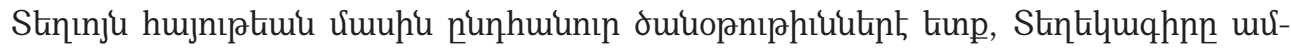

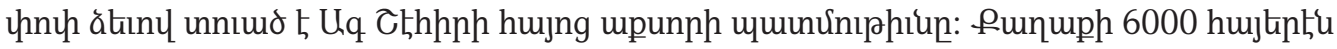

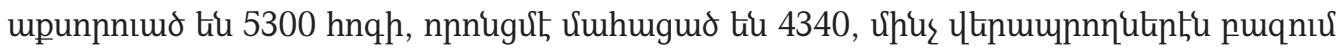

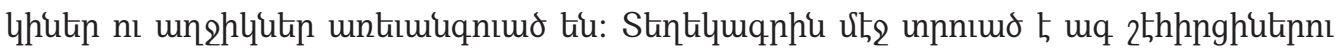

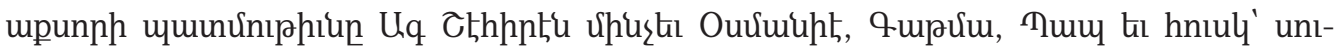
phulqui mumumin:

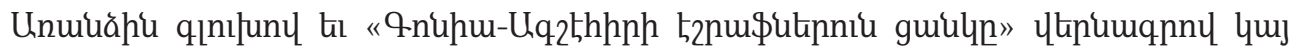

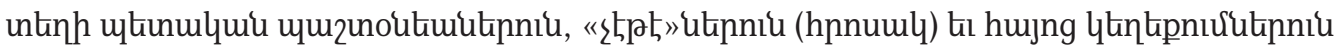

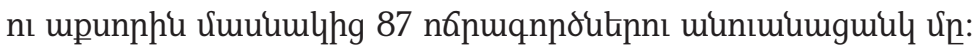

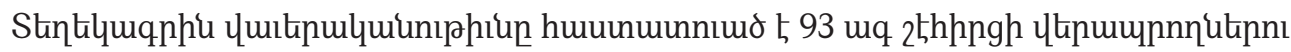
uunnnuqnnıptiuúp:

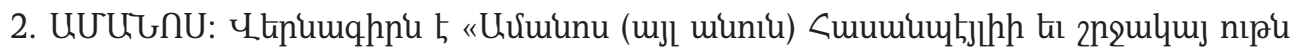

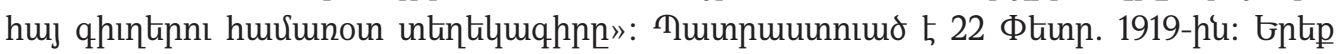

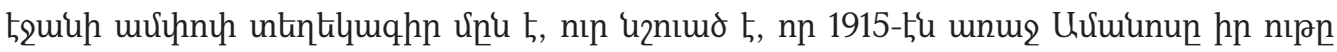

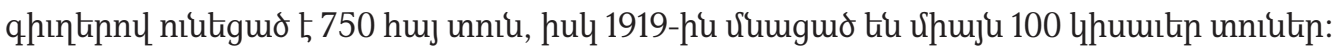

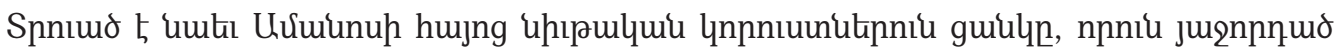

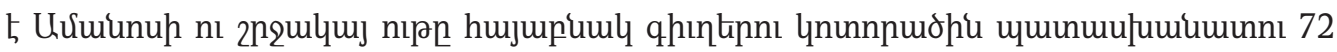

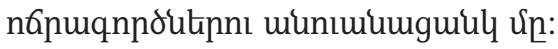

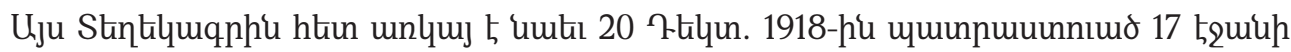

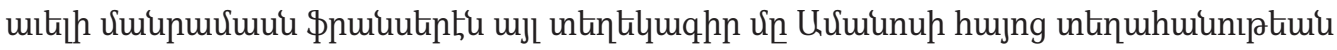

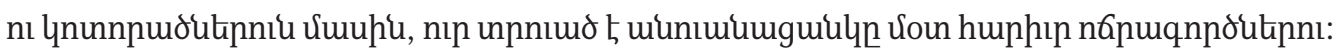

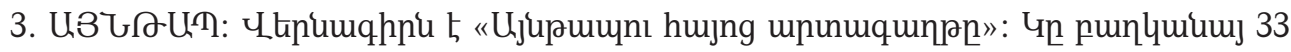
Uthounhn h, tiph:

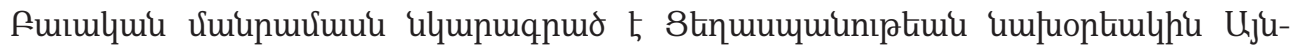

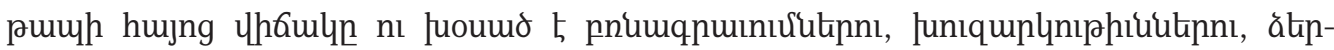

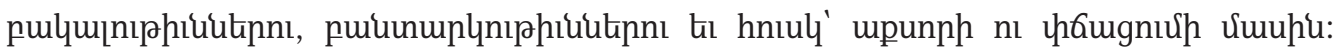

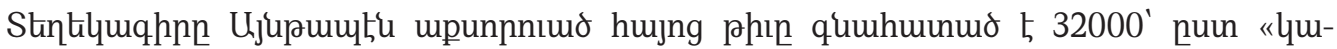

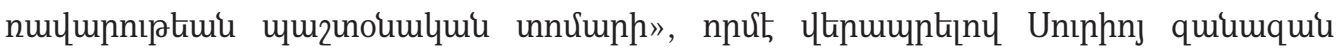

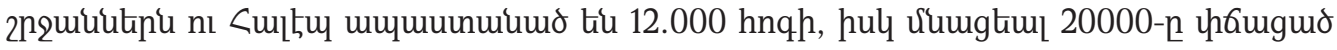

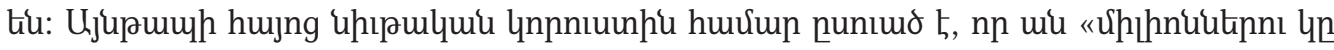

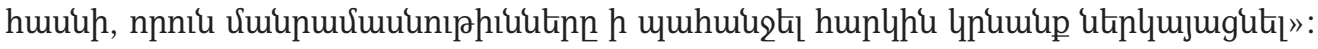

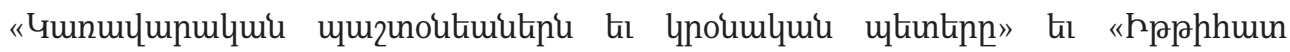

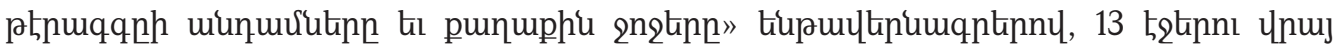

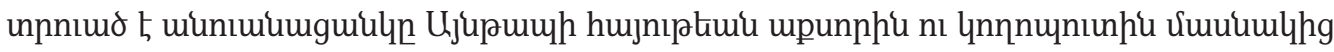

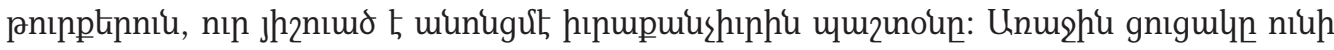

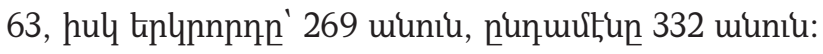

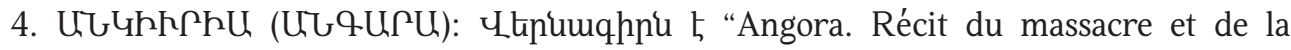

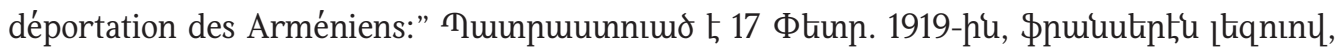

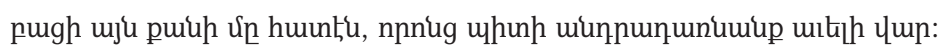




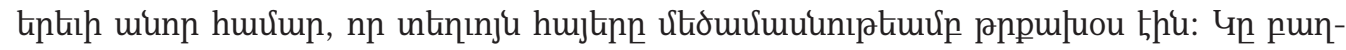

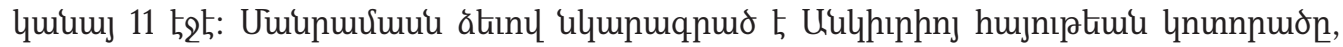

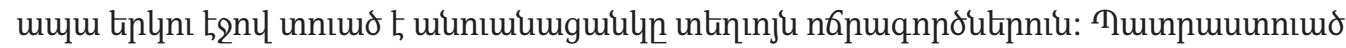

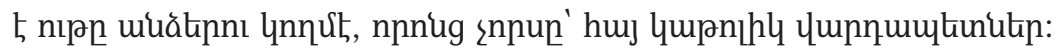

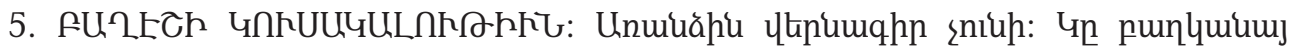

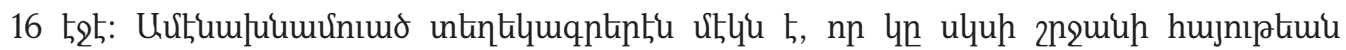

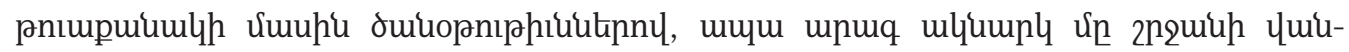

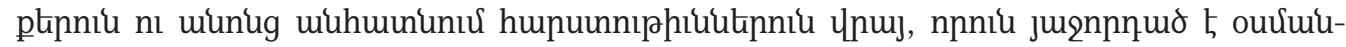

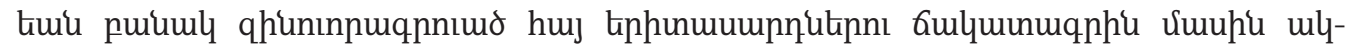

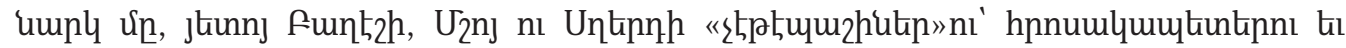

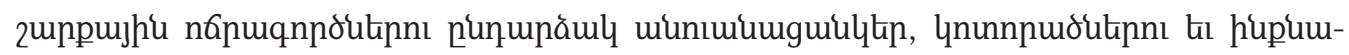

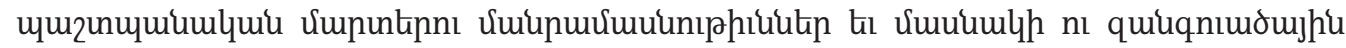

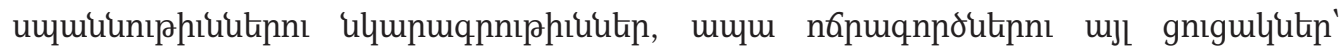

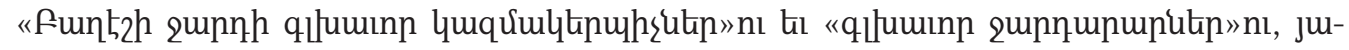

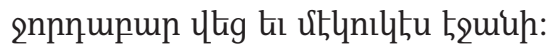

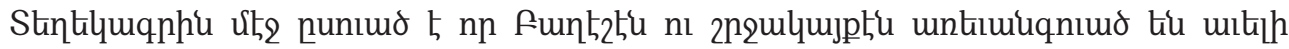

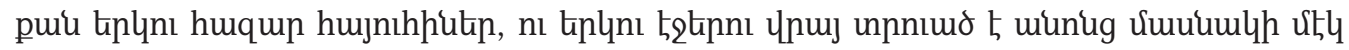

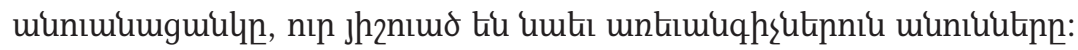

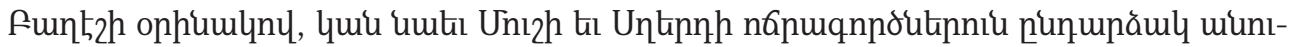

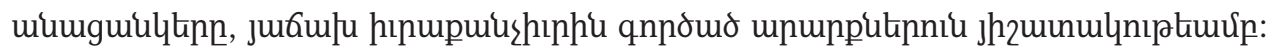

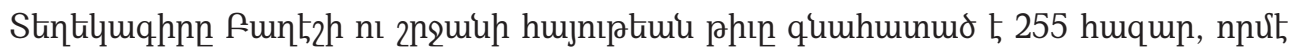

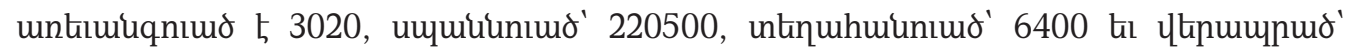

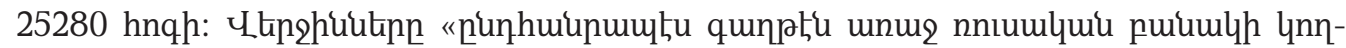

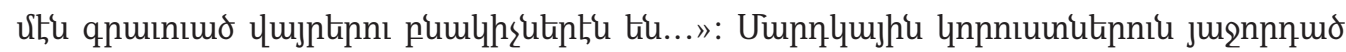

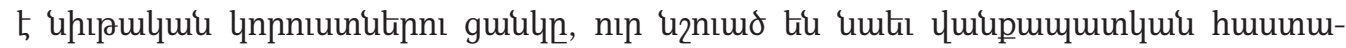

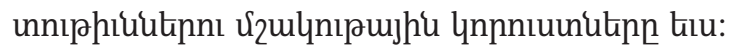

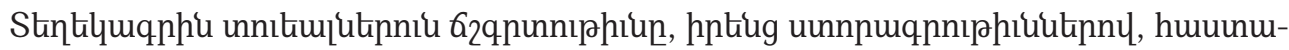

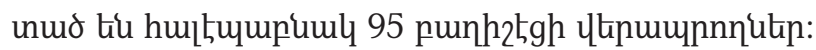

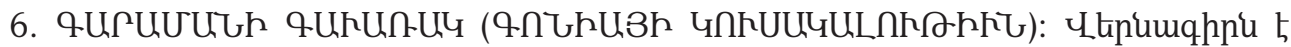

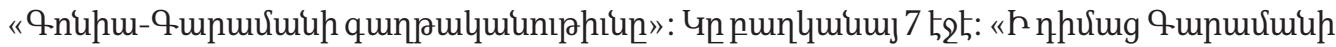

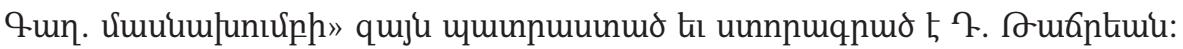

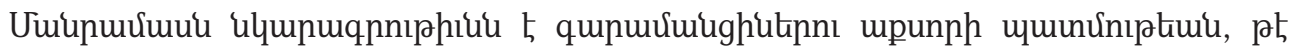

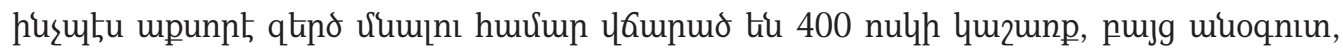

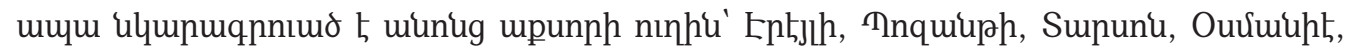

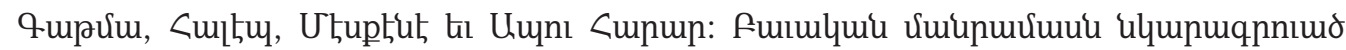

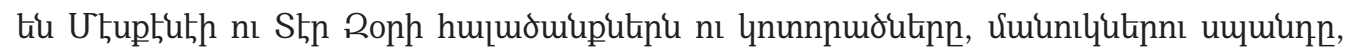
ki ujlu:

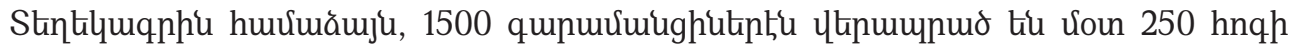
uhuju: 


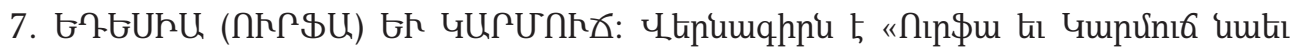

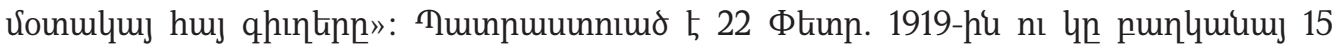
t, thint:

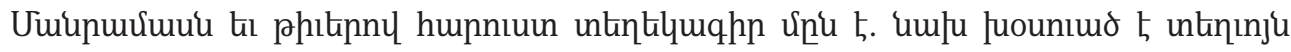

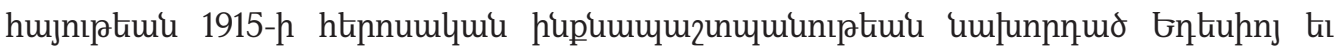

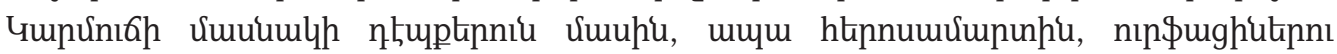

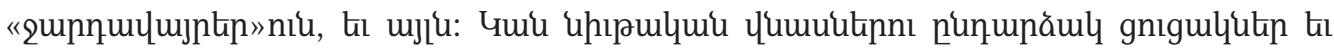

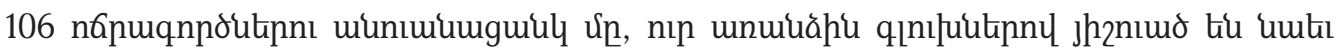

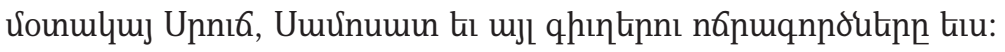

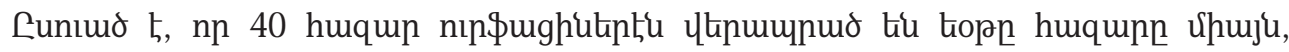

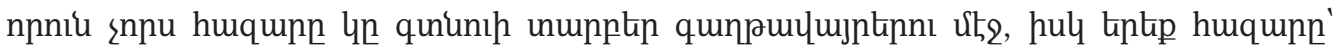
oununutinn huphưutnn:

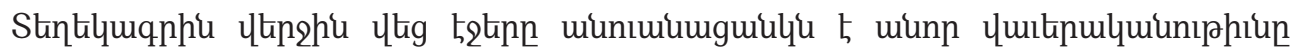

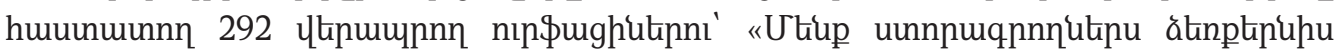

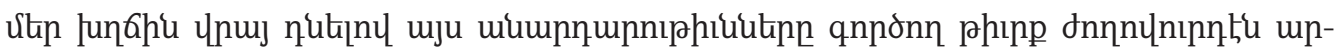

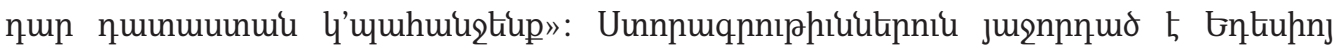

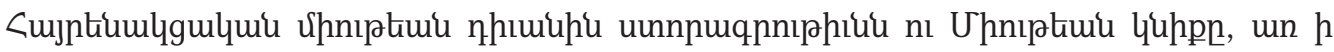

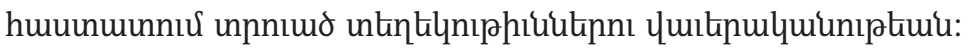

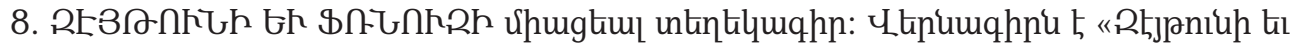

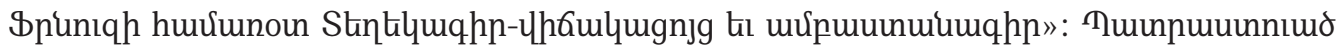
5 27 Фtinn. 1919-hu:

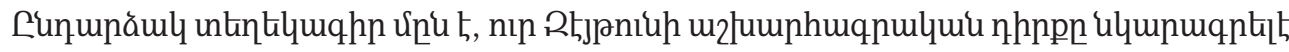

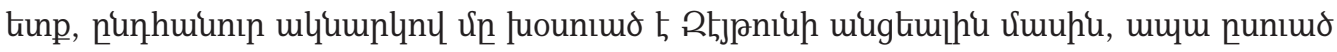
5, nn Фtinn. 1915-hu Uunuzh tiptikih hpphhuunulqui pnınptip, phınц 2750 hnqh,

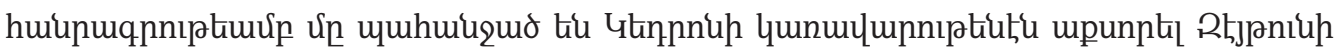

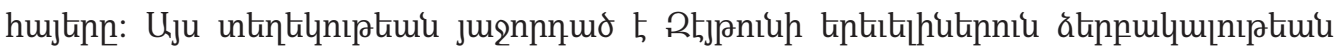

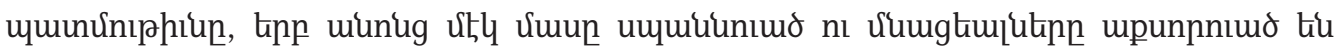

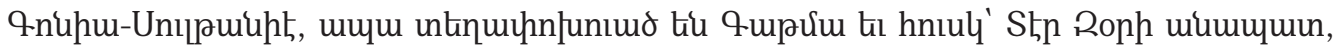

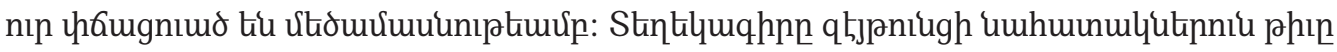
qumhumuro 5 27500-nц:

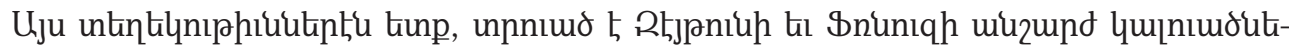

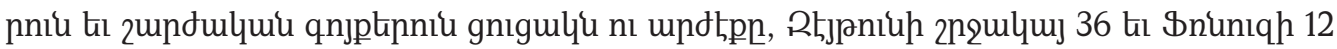

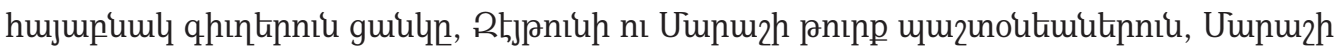

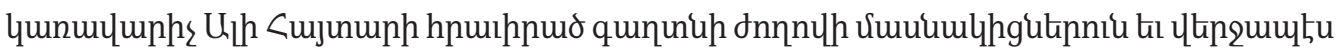

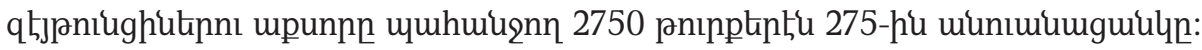

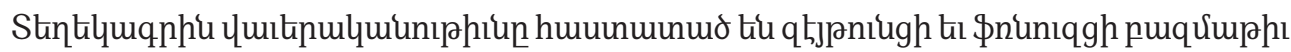
yknumpnnutip:

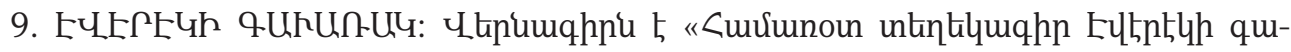

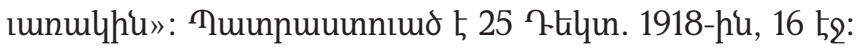

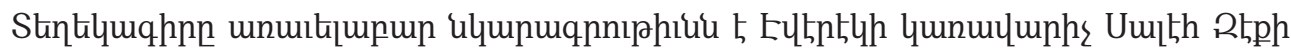




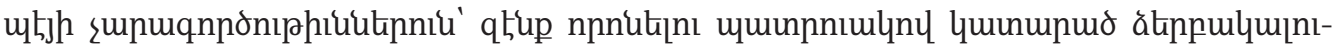

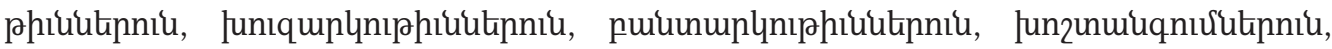

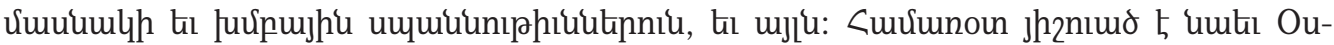

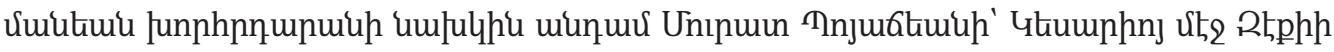

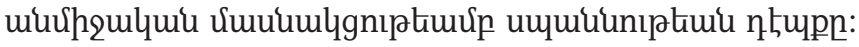

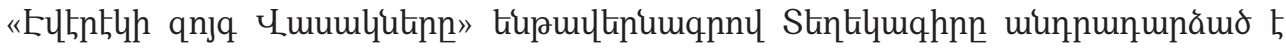

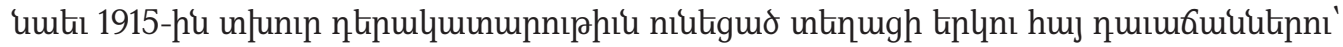

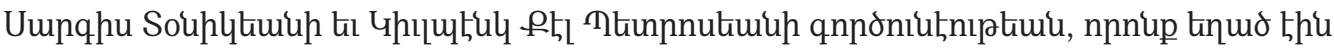

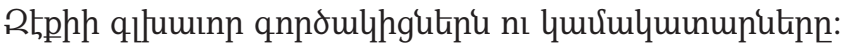

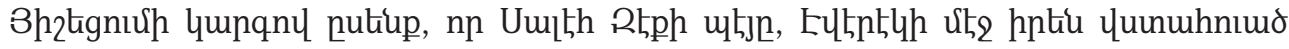

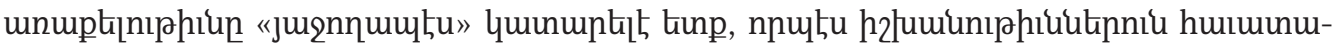

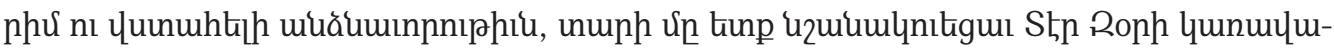

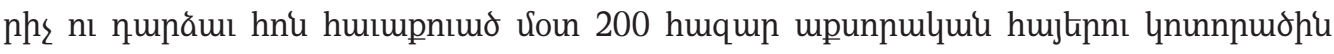
qlluminn hpuqnnonnn:

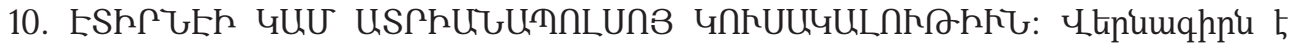

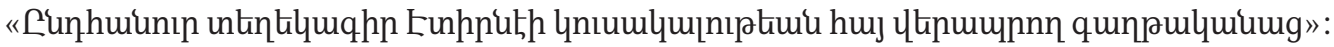

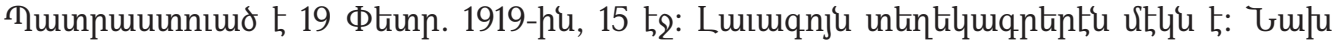

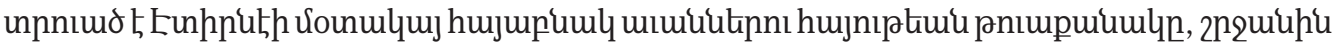

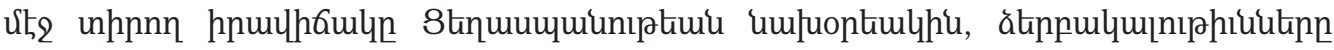

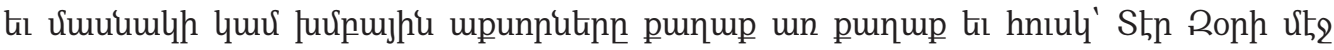
tunhputghutipnı lnunnnuor:

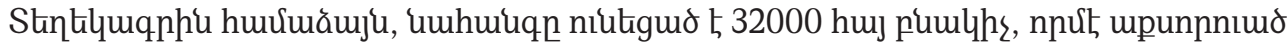
Ł 25800 nı पnunnpniwó' 23500 hnqh:

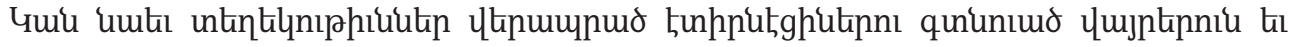

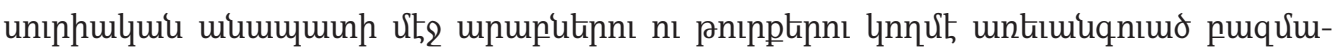

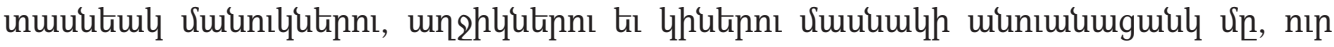

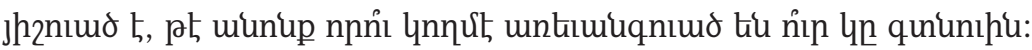

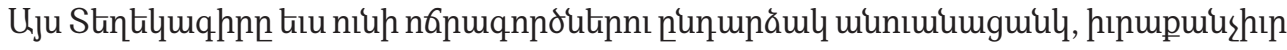
uımu unmuăhu-mnmuăhu:

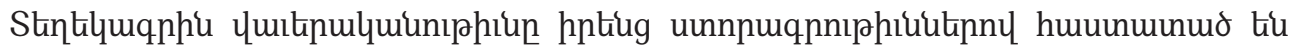
kunputgh 80 ulnuwünnutin:

11. GUคh

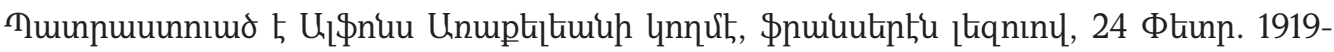

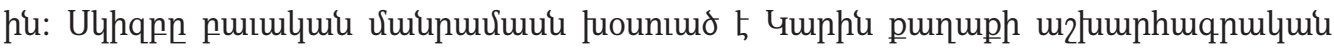

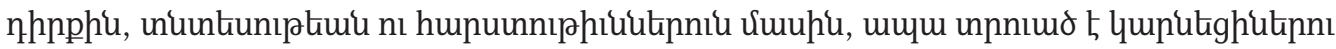

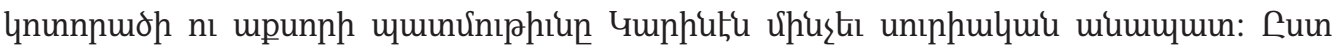

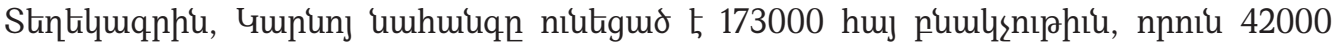

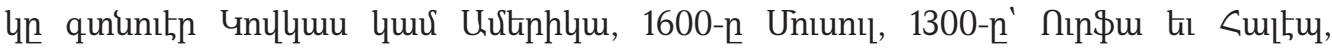

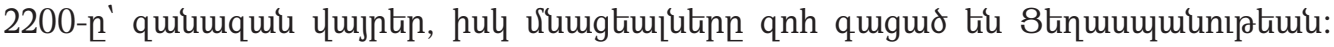




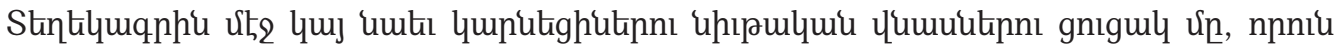

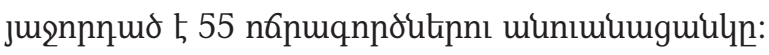

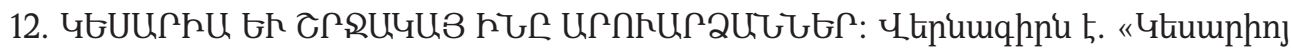

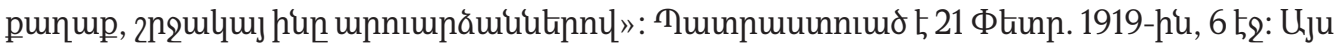

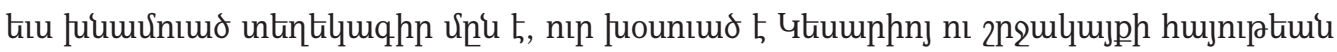

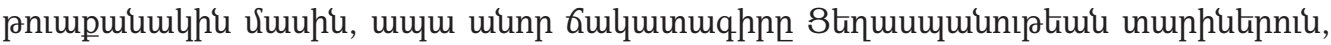

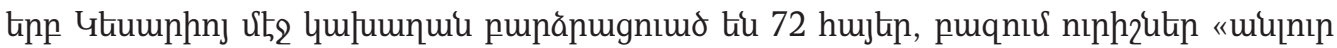

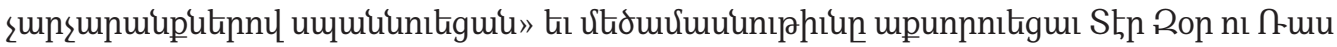

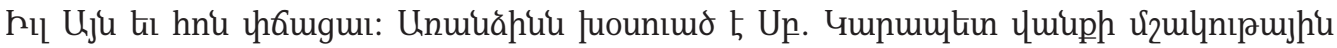

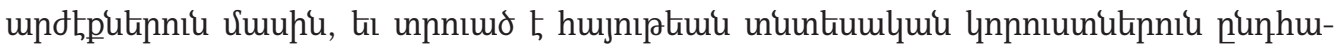
unip qumhumulquin:

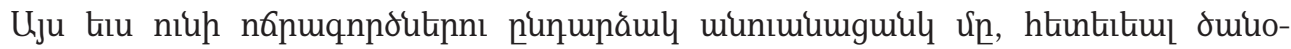

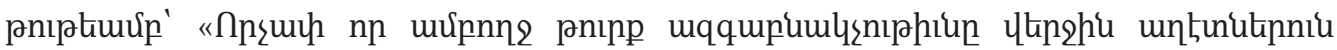

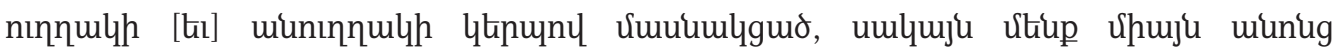

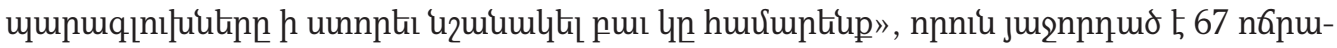
qnnơkinnı munımumgumul un:

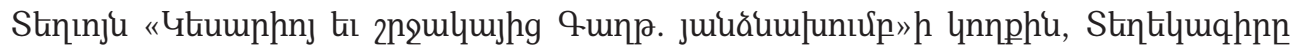

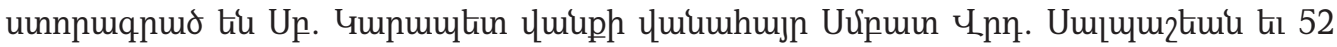
yknmumnnutin:

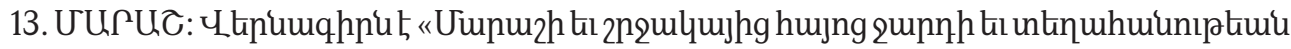

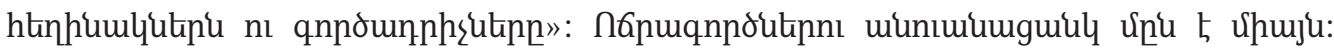

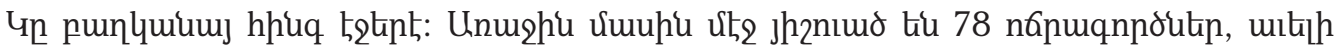

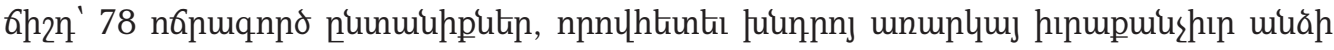

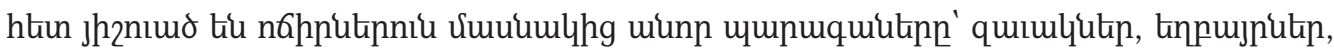

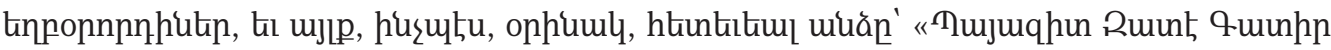

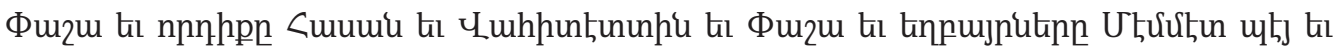

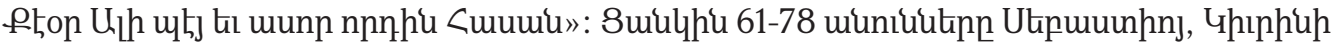

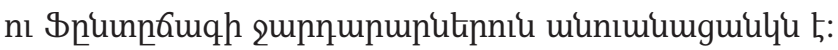

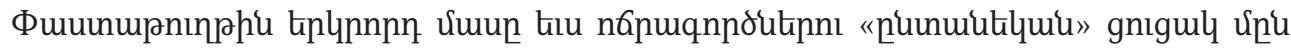

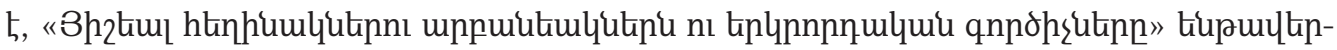

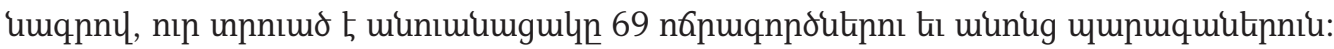

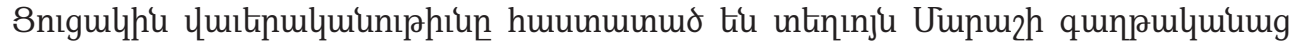

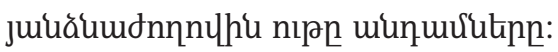

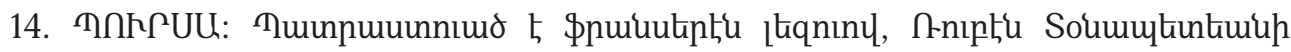

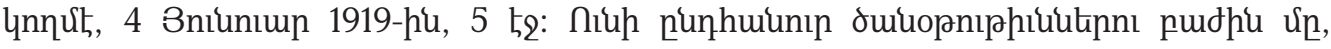

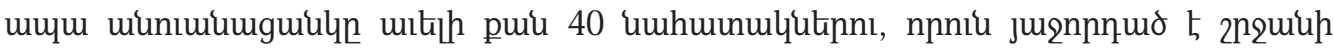
n6nuqnnơutipniu munımumguulyn: 
15. UUUnR

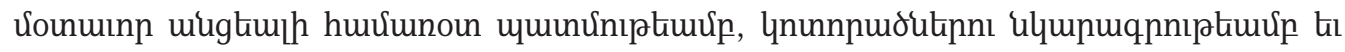

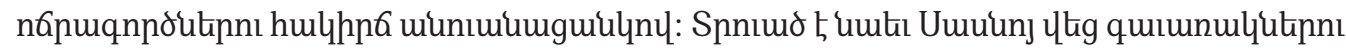

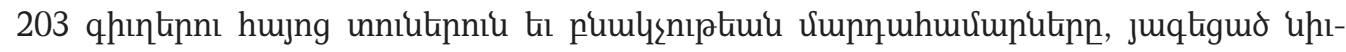

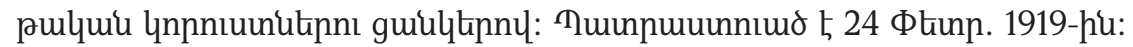

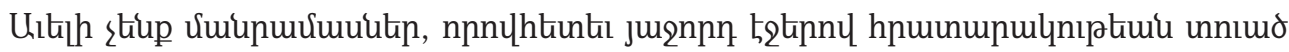

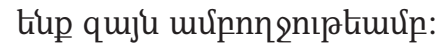

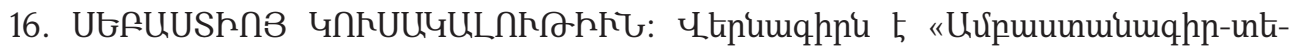

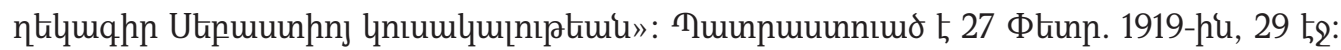

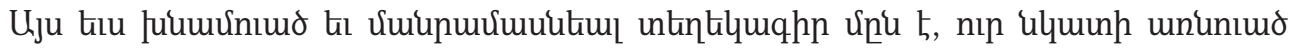

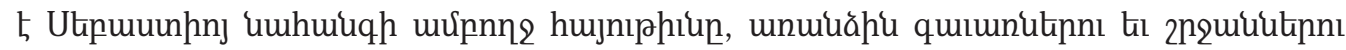
purduinnưkitinny:

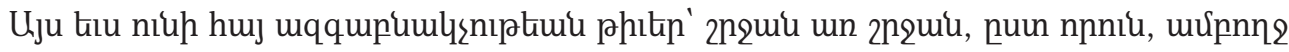

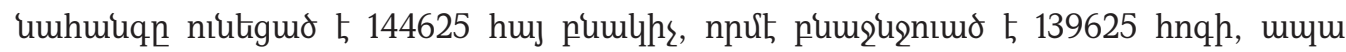

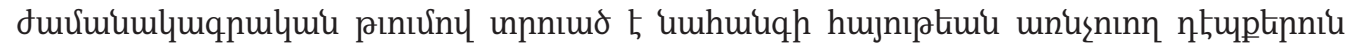

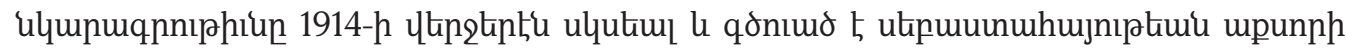

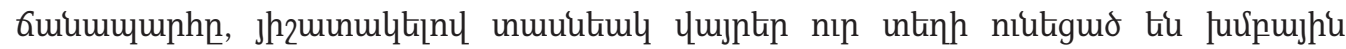

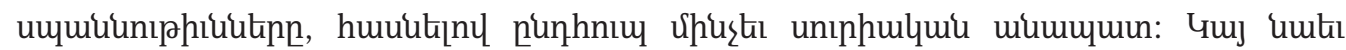

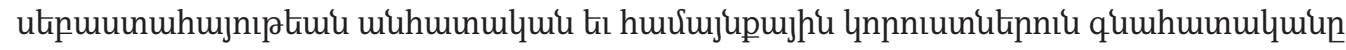

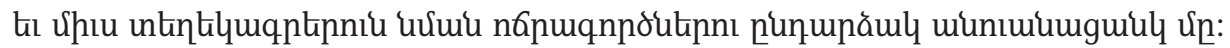

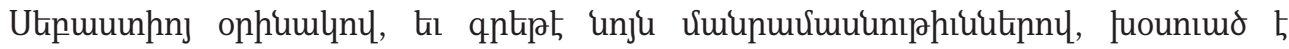

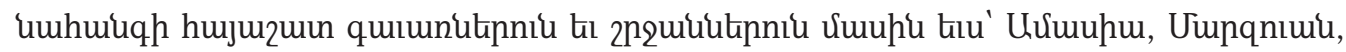

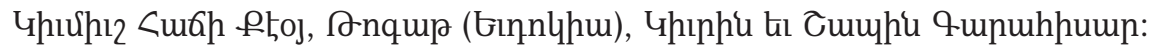

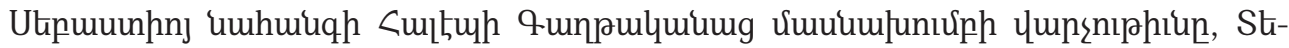

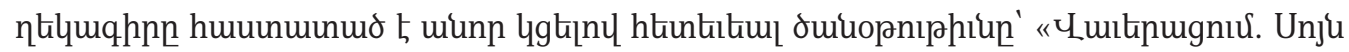

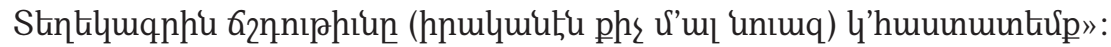

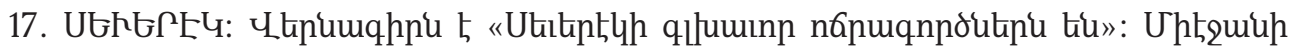

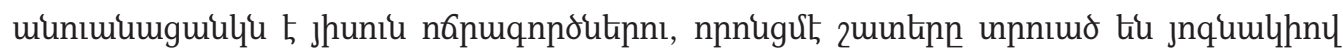

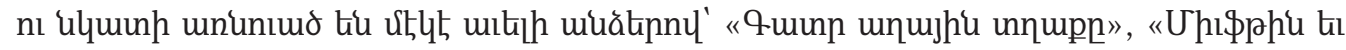

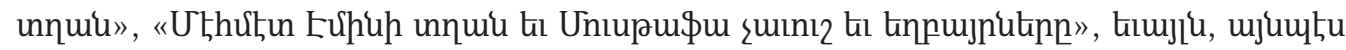

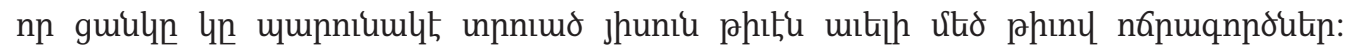

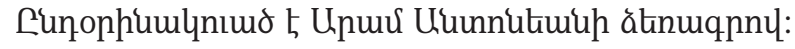

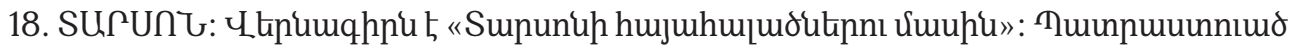

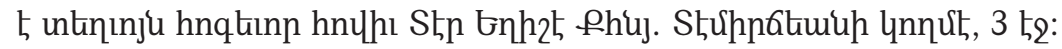

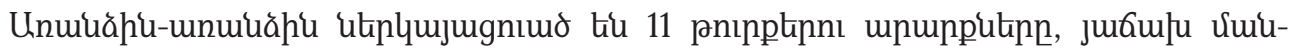

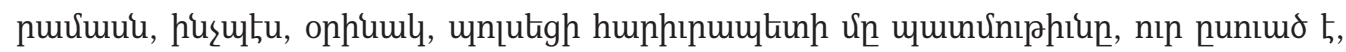

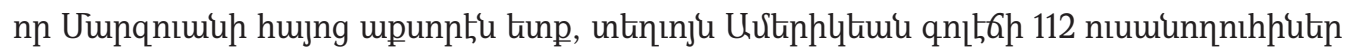

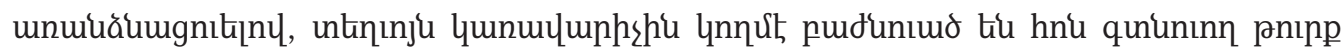




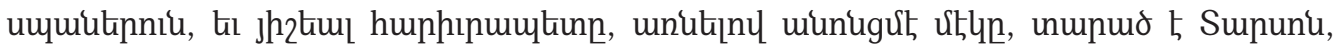

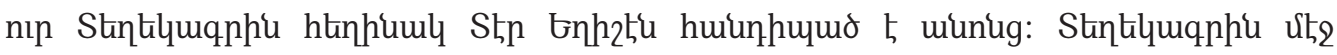

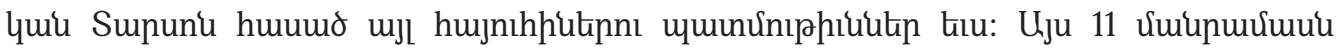

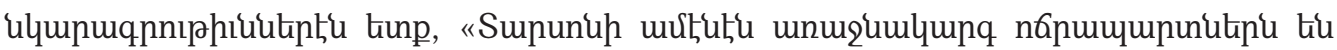

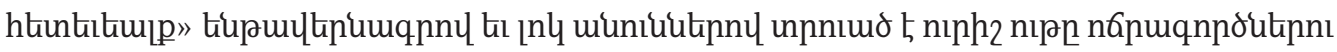
munimiumguily un:

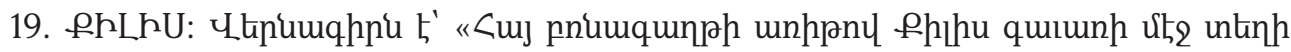

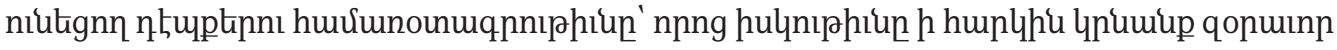

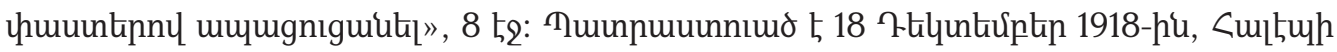

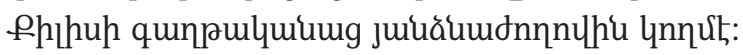

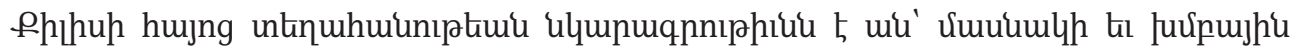

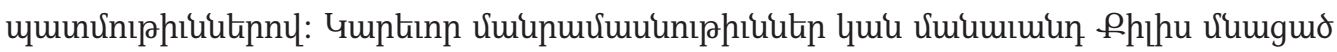

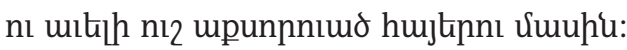

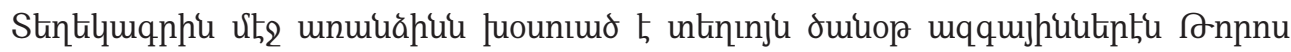

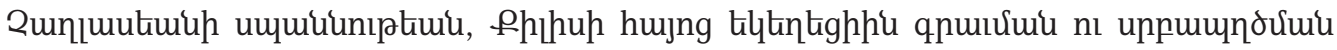

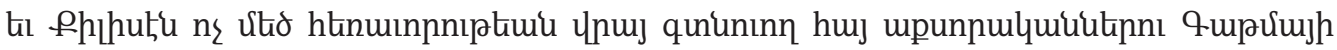
hưumlitnnnumgrumu दujphi umupu:

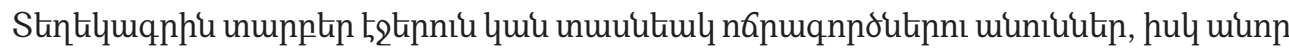

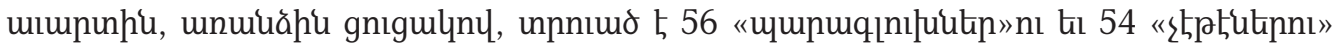
qnjq uinnumuguilltip:

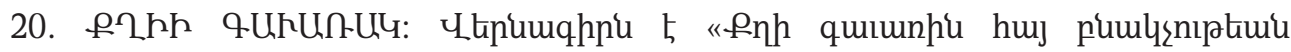
unupuqnnıphiup 1915 Uwujhu 28/11 Bniuhu»: 11 t2:

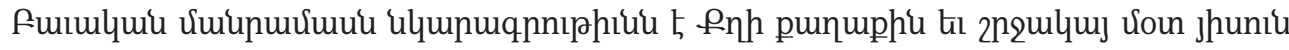

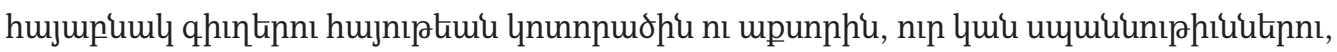

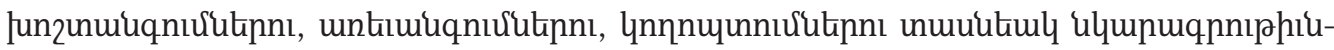

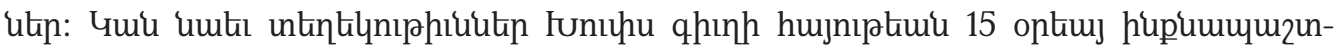

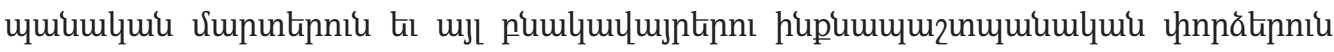
Umuni:

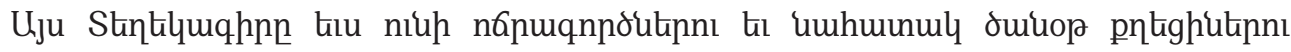
uinnumumguilytip:

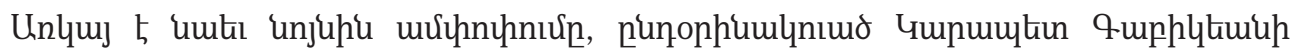
åtnumpnul:

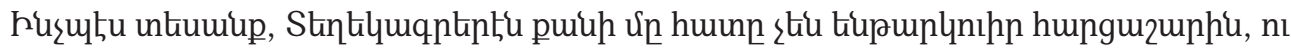

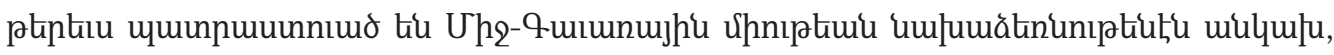

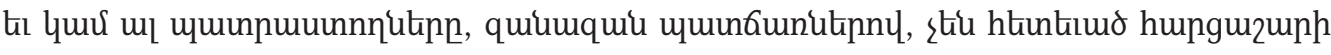

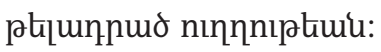

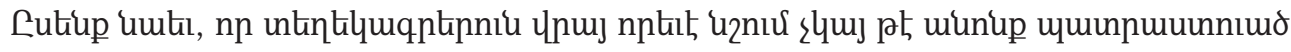

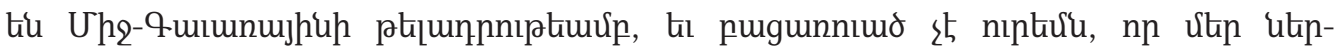




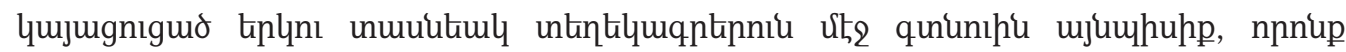

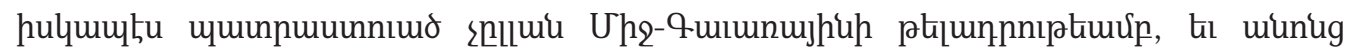

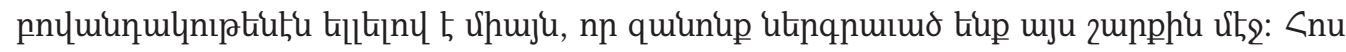

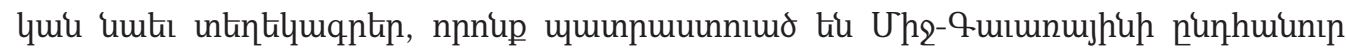

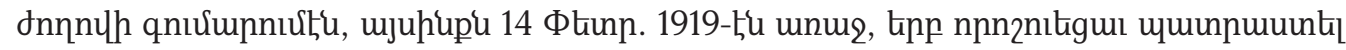

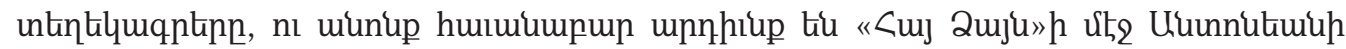

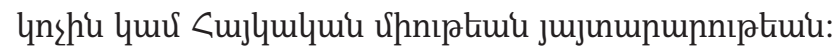

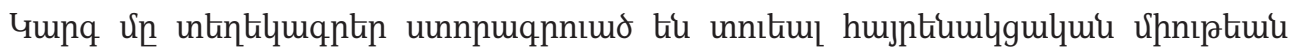

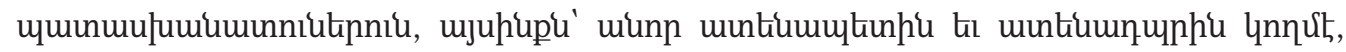

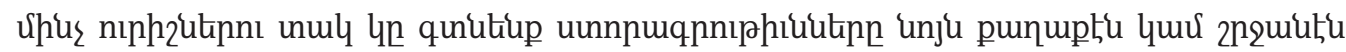

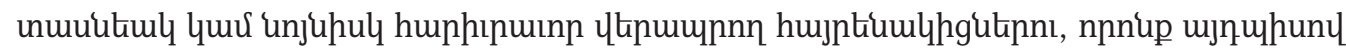

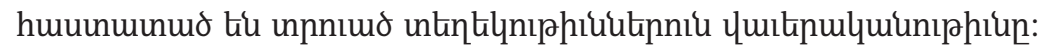

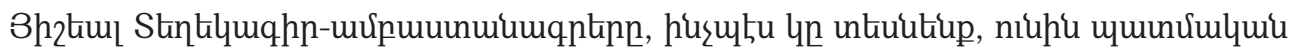

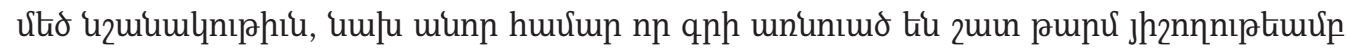

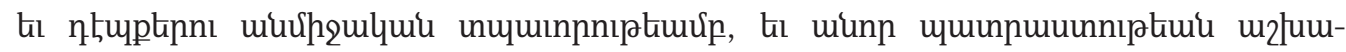

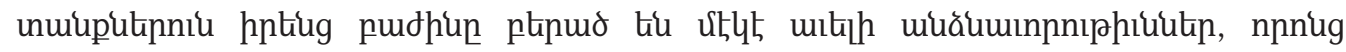

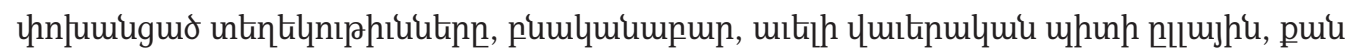

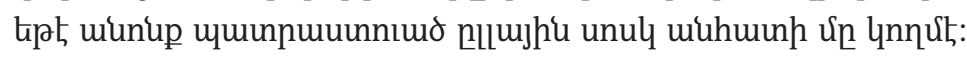

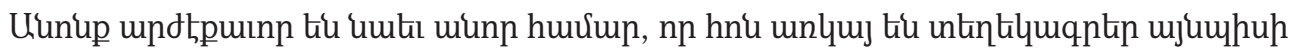

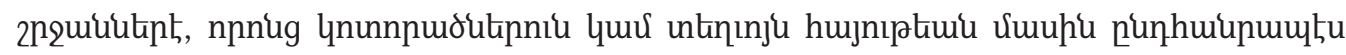

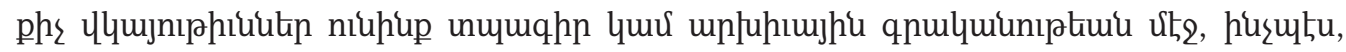

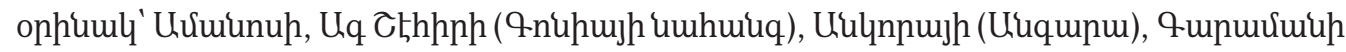

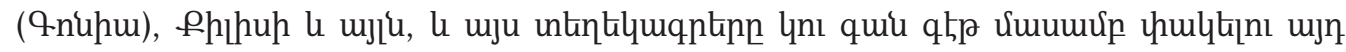

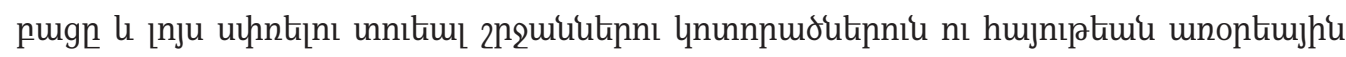
ไnü nunhwunwük:

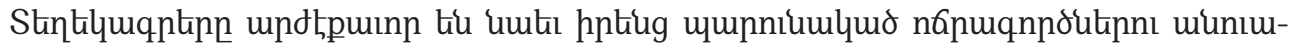

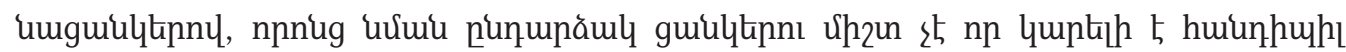

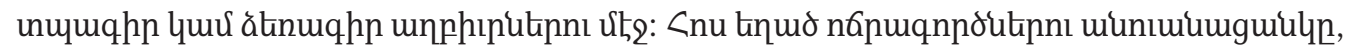

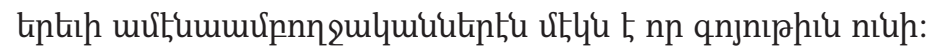

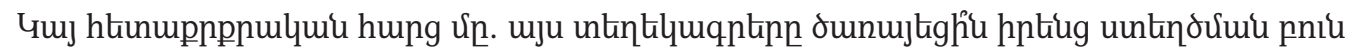

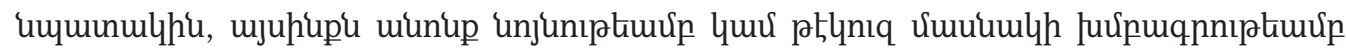

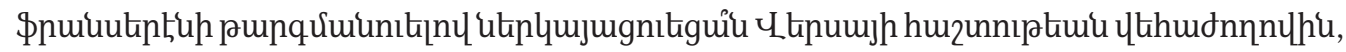

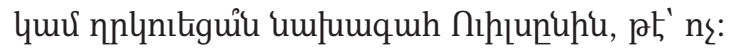

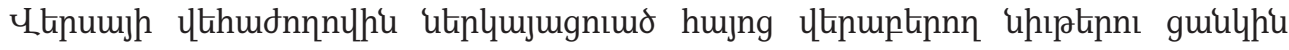

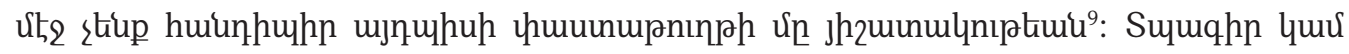

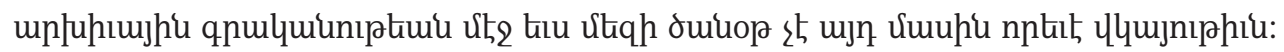

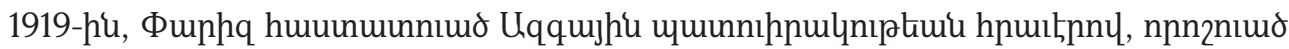

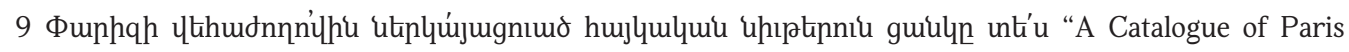




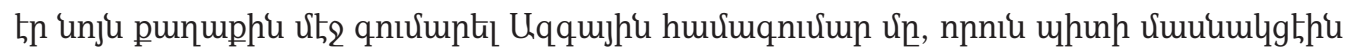

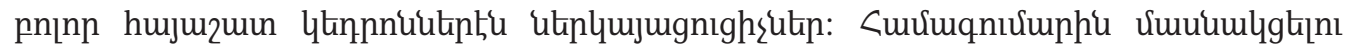

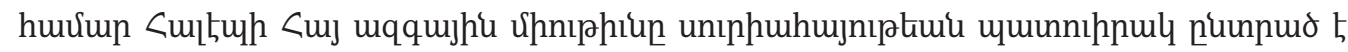

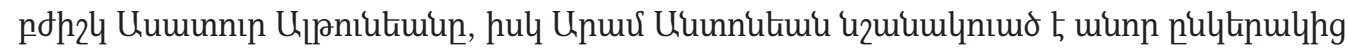

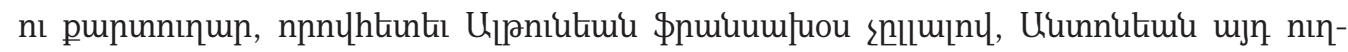

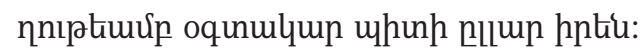

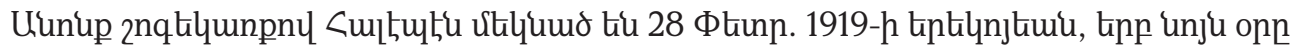

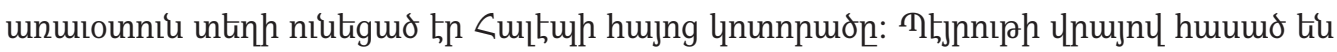

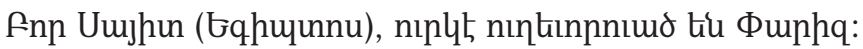

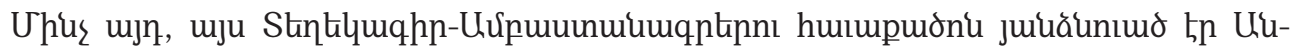

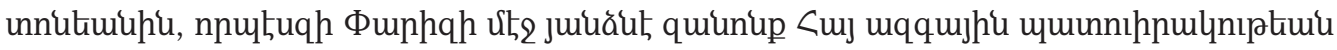

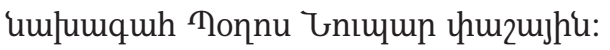

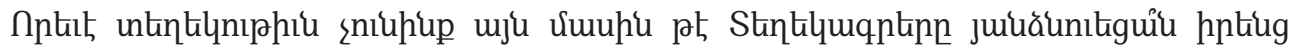

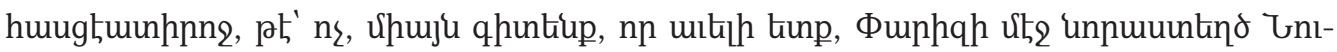

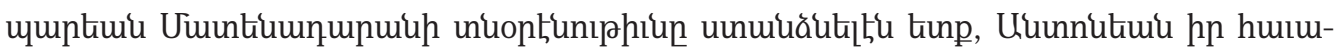

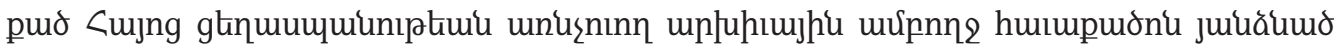

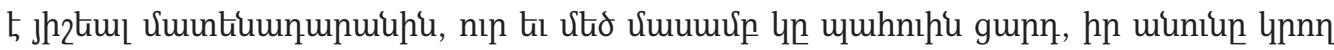

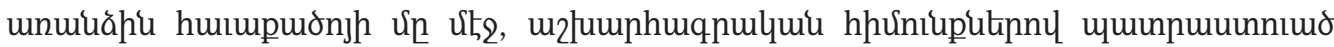

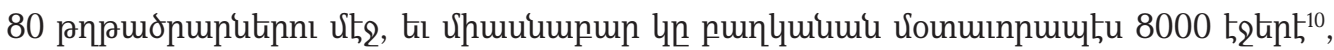

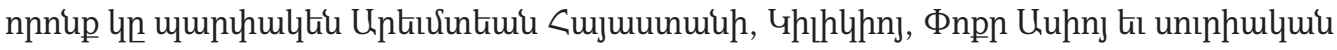

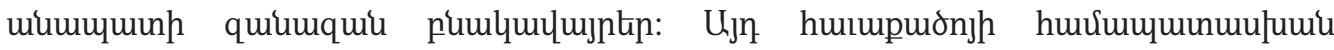

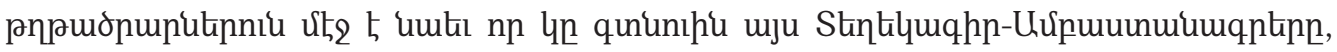
hıрupuishınn hn punuphi juinnıl uhıptipnı zunphi:

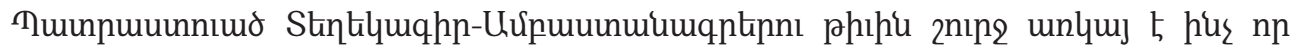

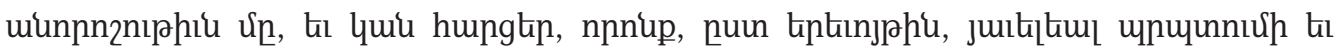
nıumpuinıрtiuu ln qunounh:

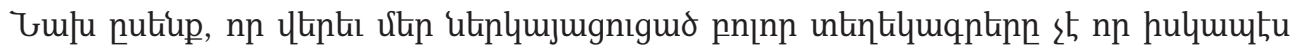

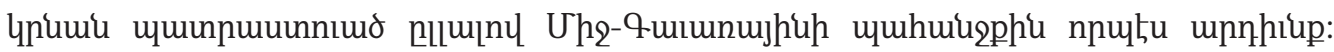

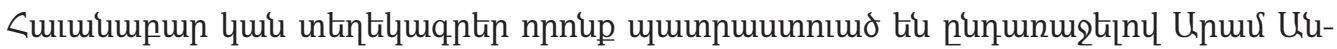

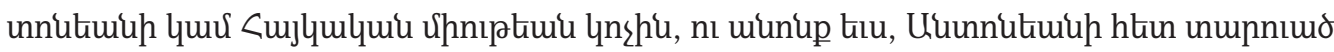

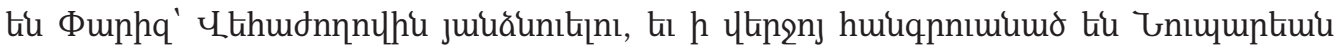
vemintiumunui:

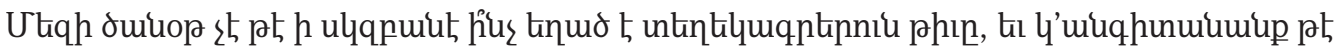

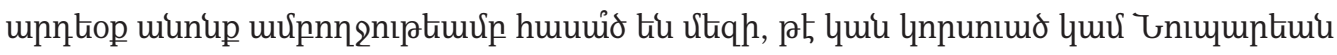

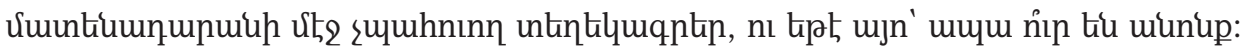

Peace Conference Delegation Propaganda in the Hoover War library" (California, 1926), 7, 19-22:

10 Boris Adjemian et Raymond Kévorkian, "Témoignages de rescapés et connaissance du génocide de 19151916,” Études arméniennes contemporaines 5(2015): 79-110: 


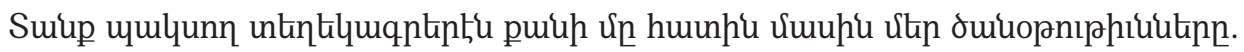

Uqqujhu ti qnulquiu qnnohs Cujluqqniu Unưरtuuu, np husuthu untumup, 1919-

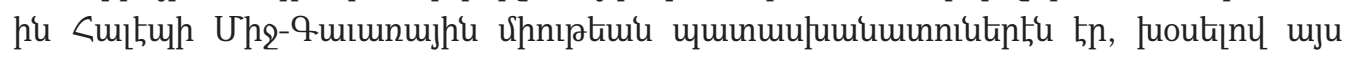

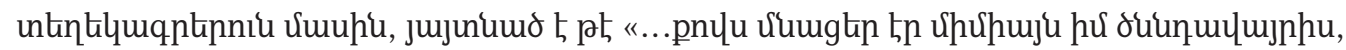

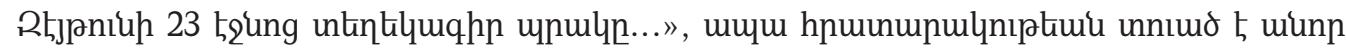

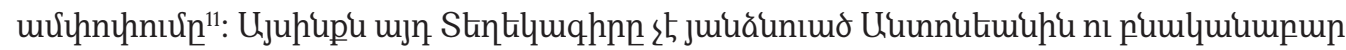

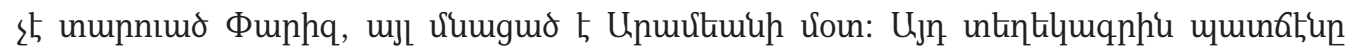

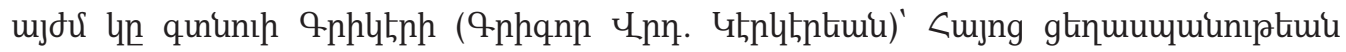

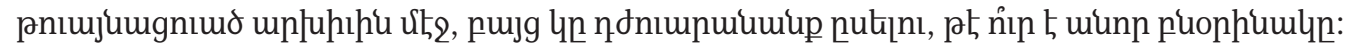

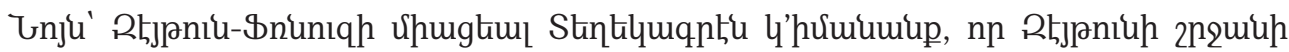

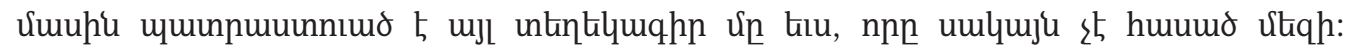

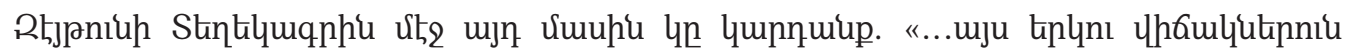

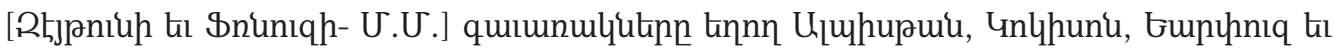

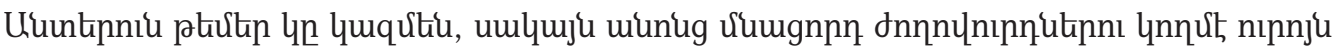

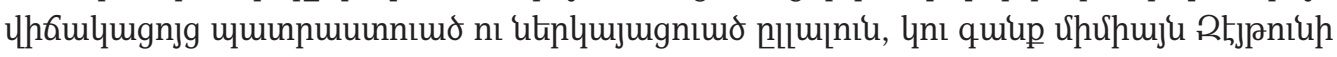

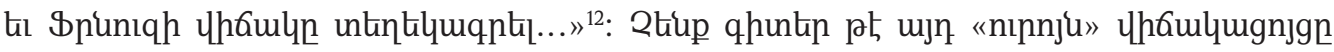

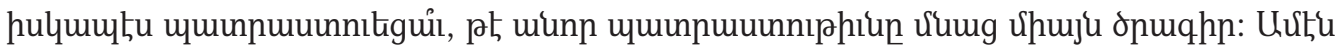

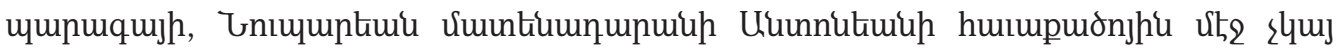
ujnuphuh untintlumqhn:

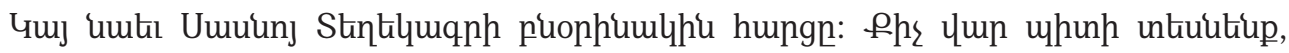

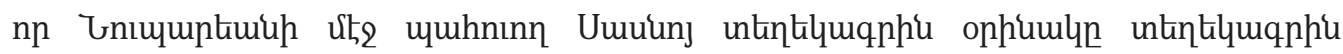

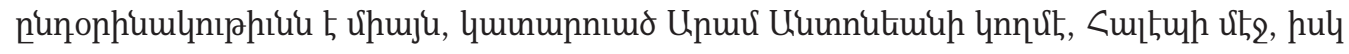

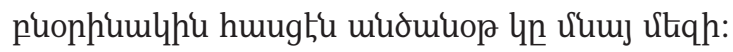

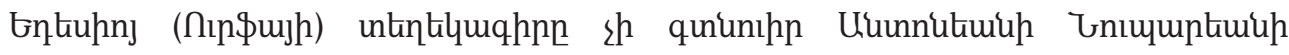

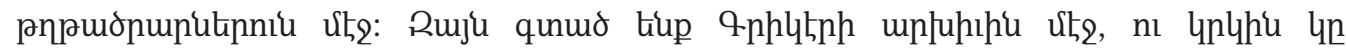

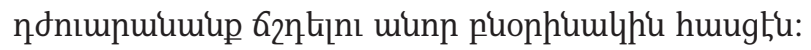

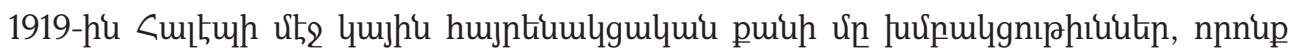

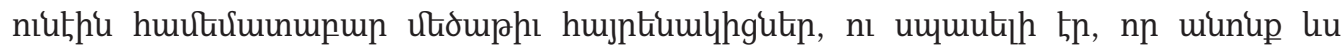

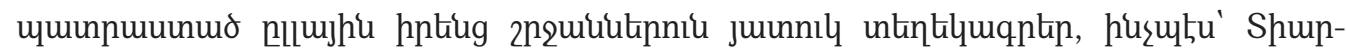

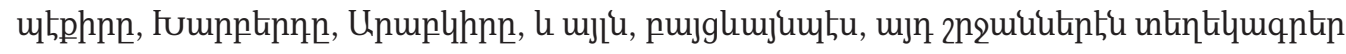

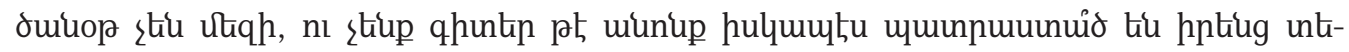
ntlumqninn, ph' ns:

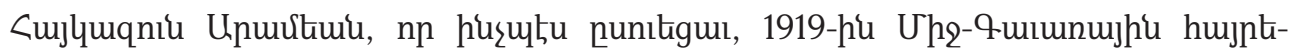

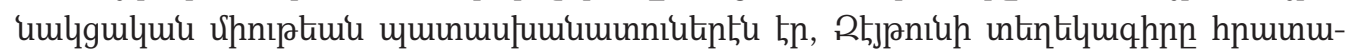

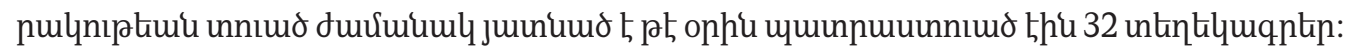

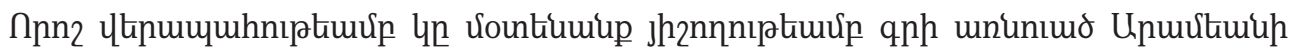

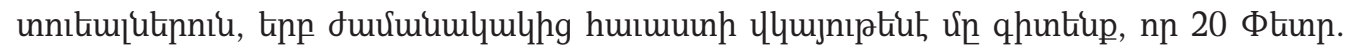

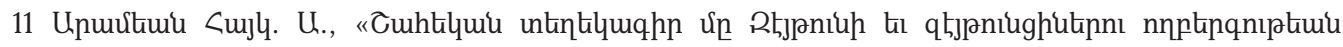

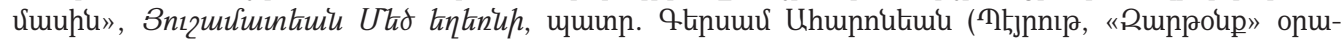

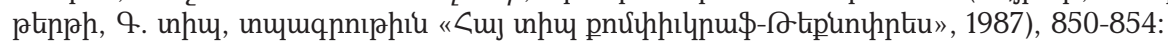

12 Unju, 851: 


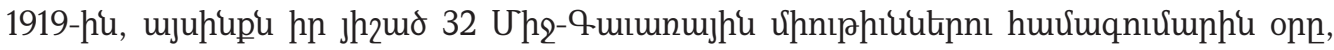

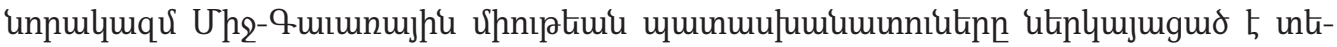

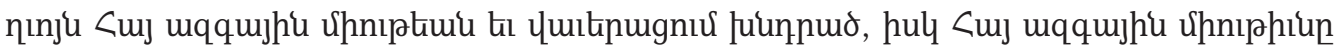

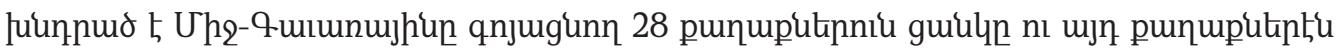

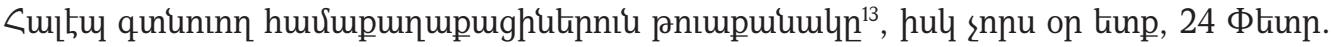

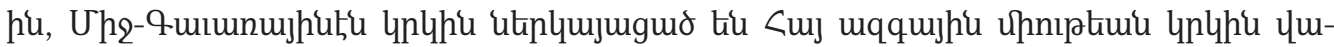

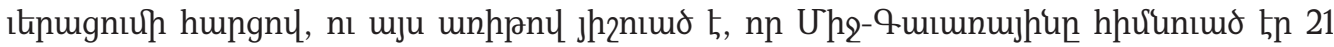

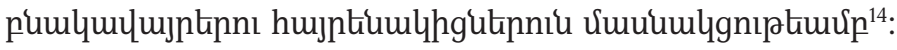

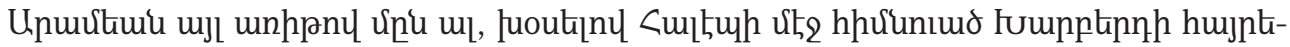

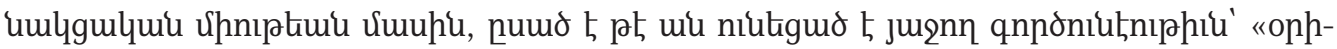

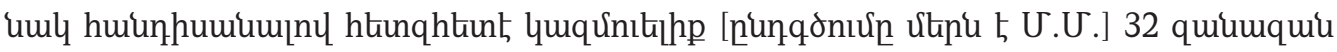

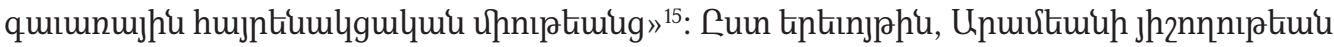

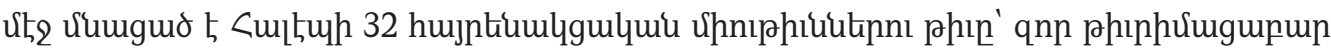

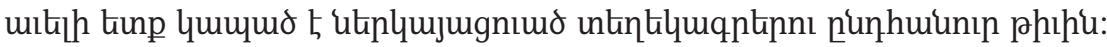

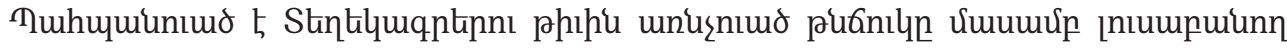

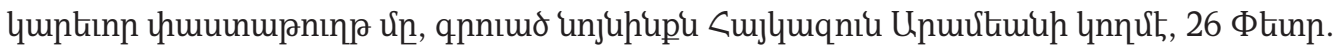
1919-hu: Suup quju unjunıрtuuup.

Qtipumumun

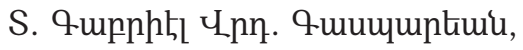

$\Phi$. umpumquih <uj uqqujhi úpnıptimu

$$
\text { Culltur }
$$

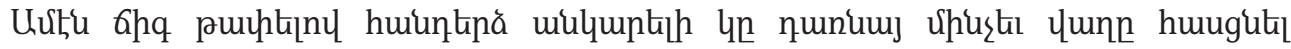

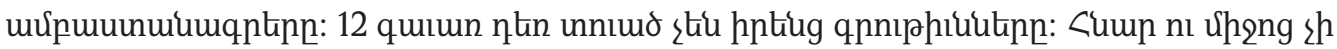

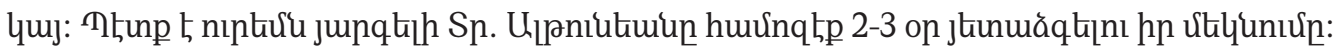

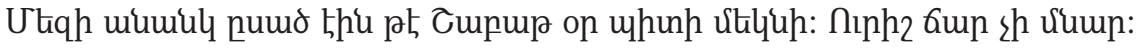

\section{<ultur \\ $26 / 2 / 19$ \\ Bupquưop åtinn

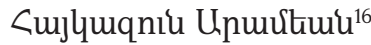

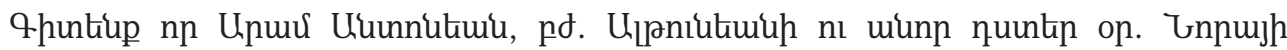

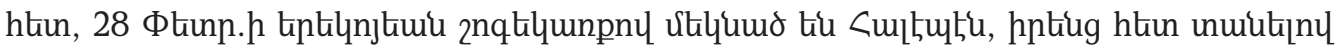

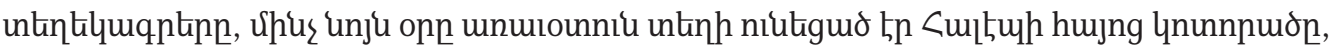

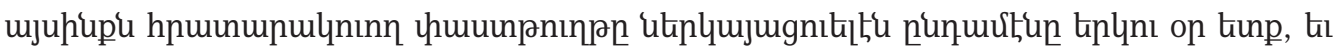

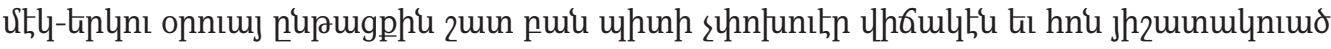

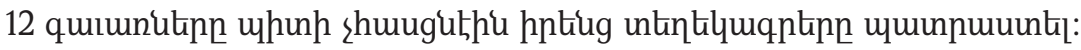

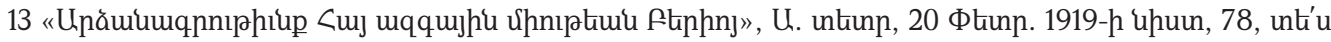

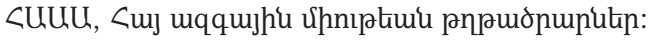

14 টnju, 24 Фtinn. 1919-h upuun, 79:

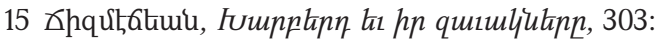

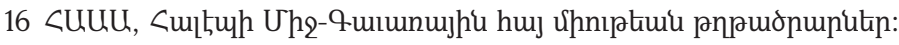




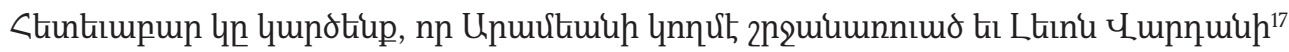

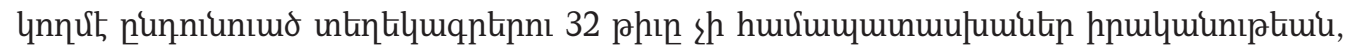

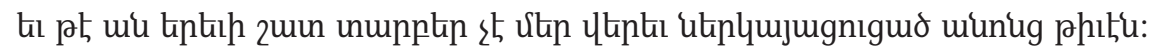

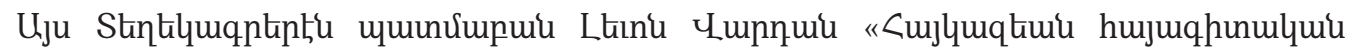

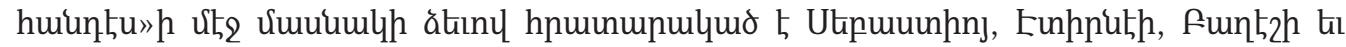

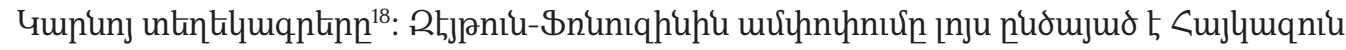

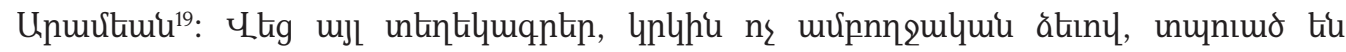

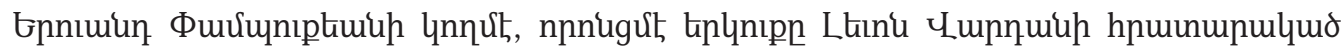

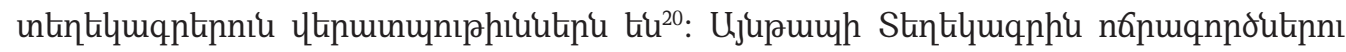

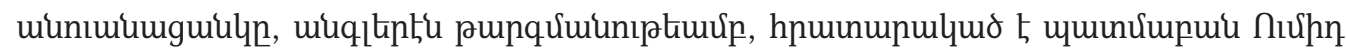

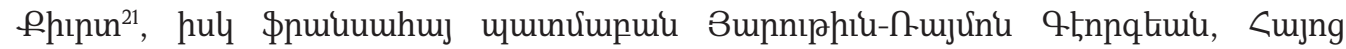

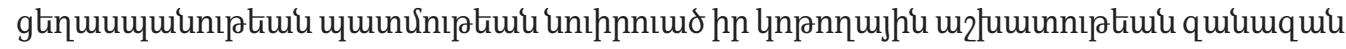

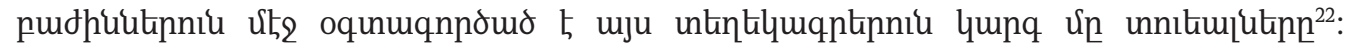

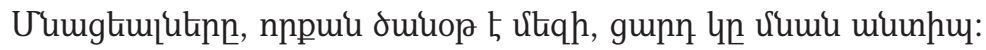

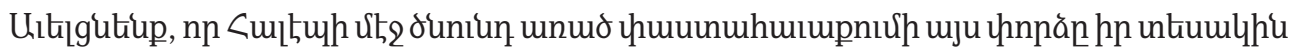

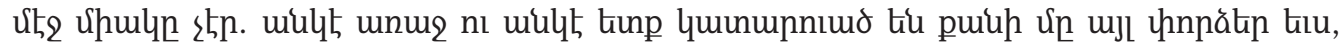

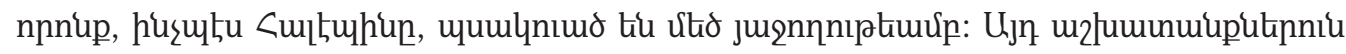

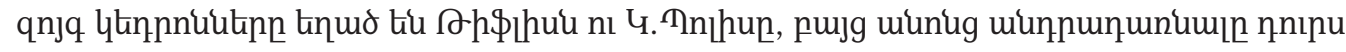

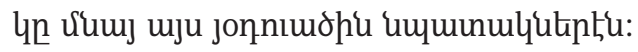

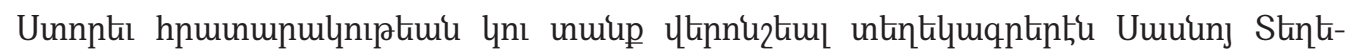

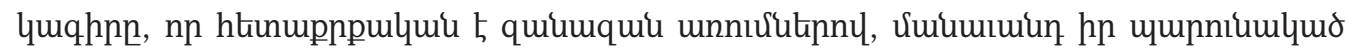

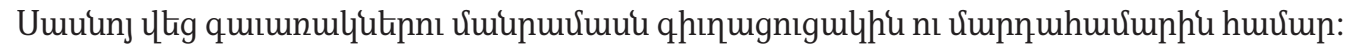

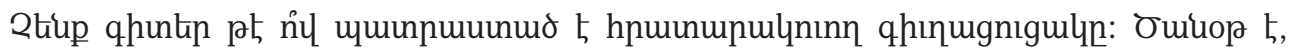

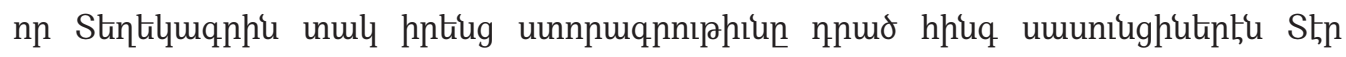

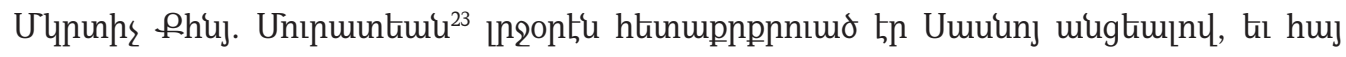

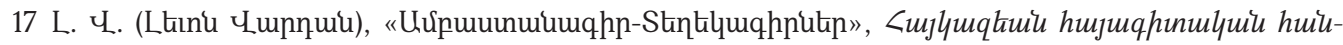
$\eta 5 u$ U (1995), 497-553:

18 Znju, 498:

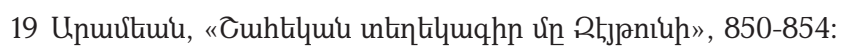

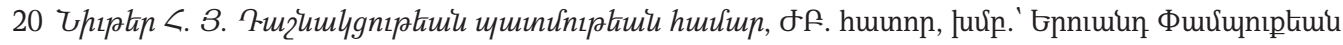
(Thjpnnip, Cunumqqujhup U.uht, Utphumu, 2016), 407-428:

21 Ümit Kurt, The Armenians of Aintab. The Economics of Genocide in an Ottoman Province (Cambridge, London: Harvard University Press, 2021), 233-240:

22 Raymond Kévorkian, “The Armenian Genocide: A Complete History” (London-New York: I. B. Tauris, 2011), 1029.

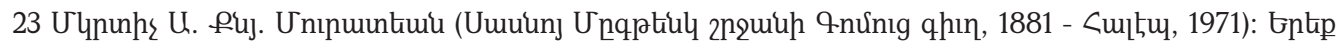

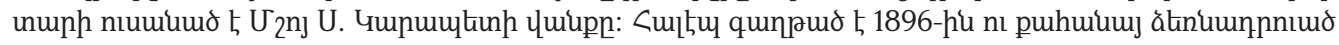




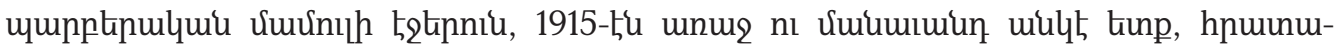

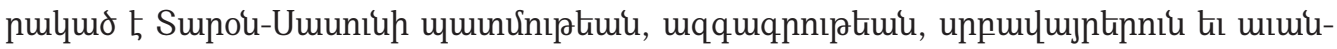

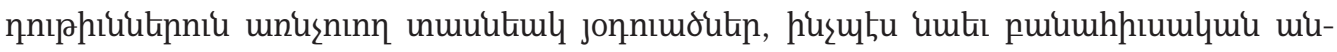

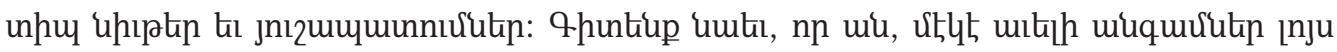

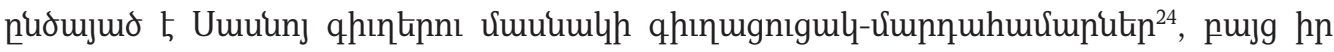

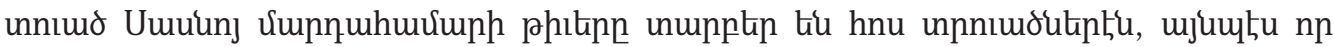

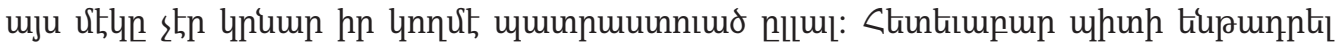

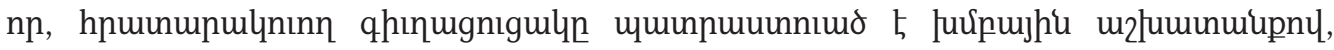

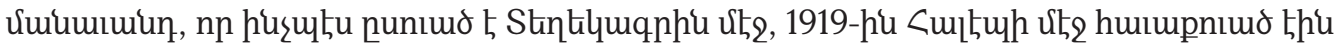

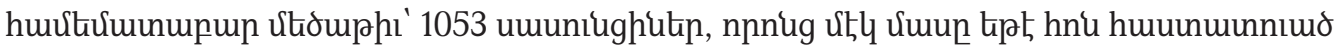

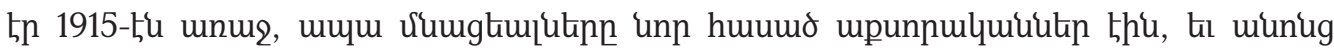

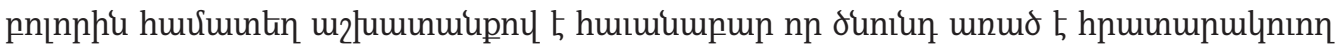
gniguly:

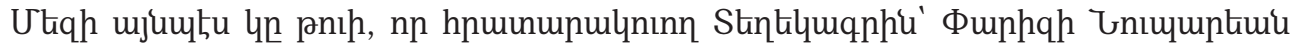

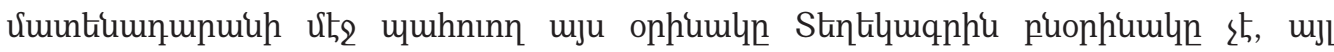

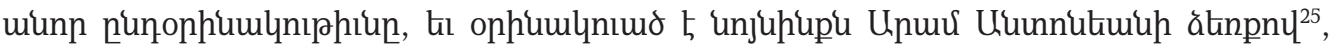

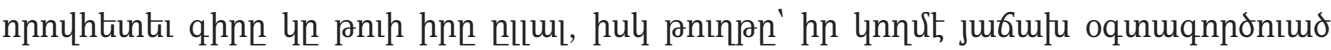

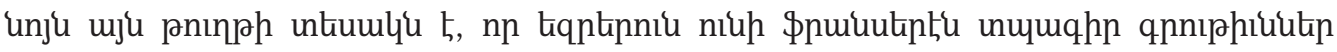

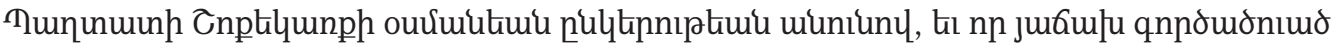

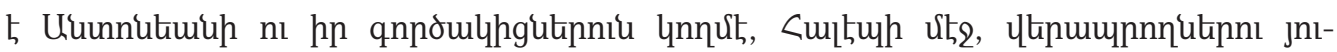

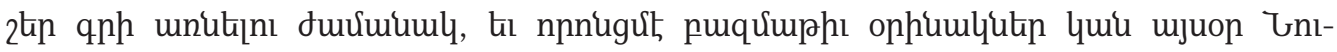

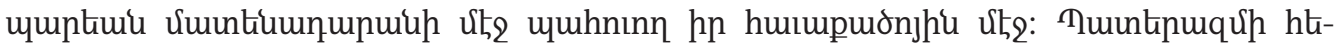

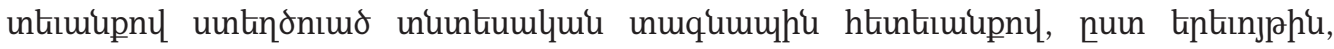

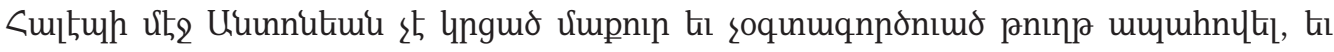

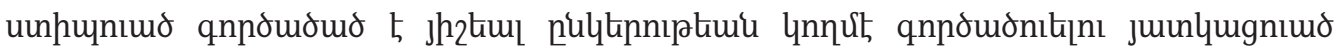

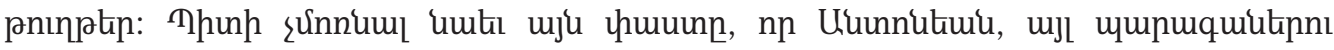

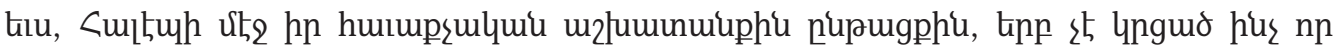

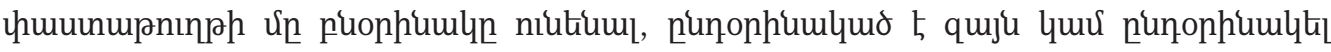

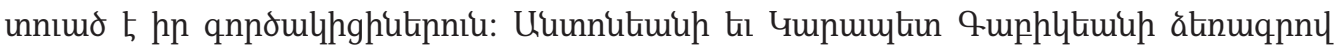

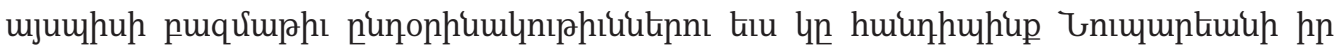

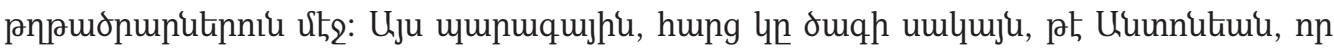

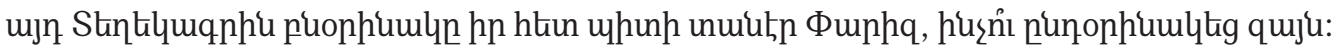

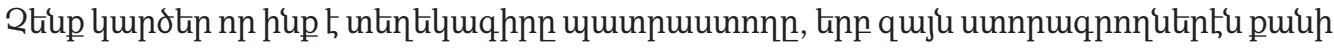

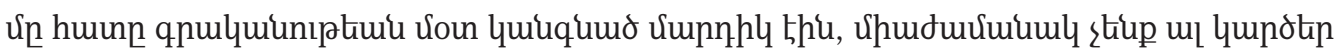

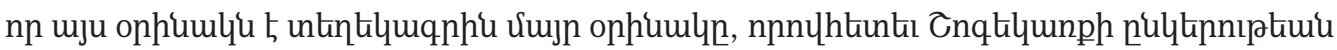

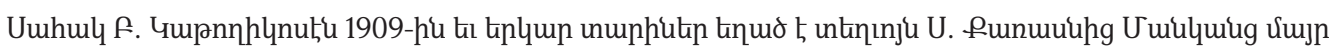
tiltintiginj dpumlumi purwuium:

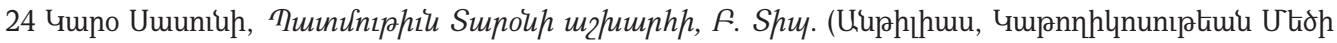
unuiu Чhцlhhn, 2013), 338:

$25 \mathrm{BNu} /$ Fonds A. Andonian - Matériaux pour l'histoire du génocide, Dossier 47, Déportations et massacre des Arméniens de Sassoun, ptupp 1-11: 


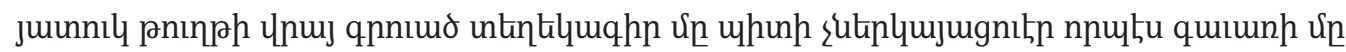

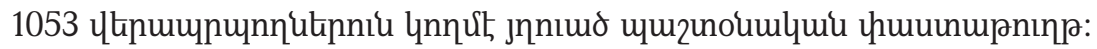

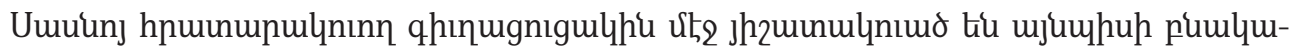

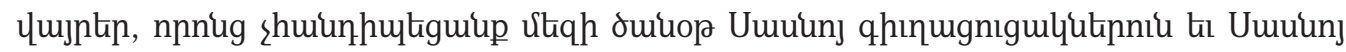

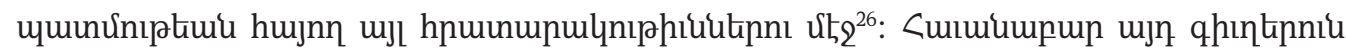

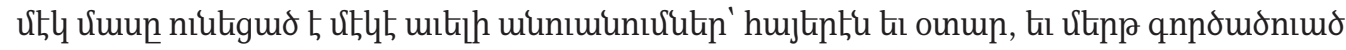

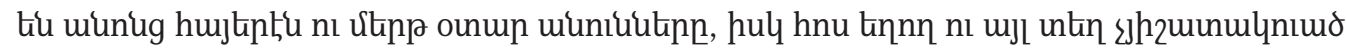

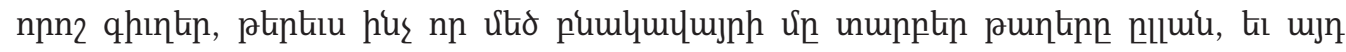

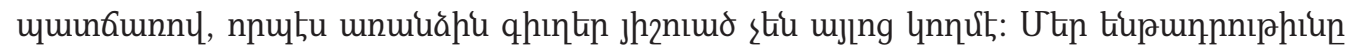

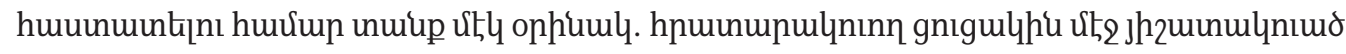

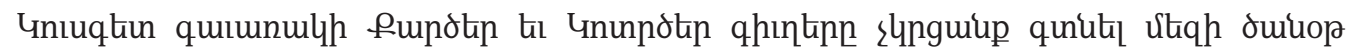

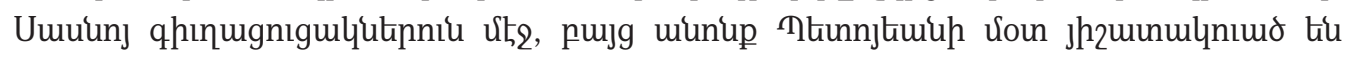

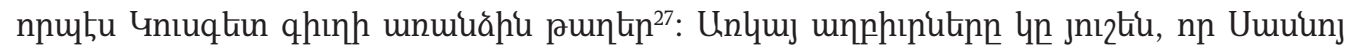

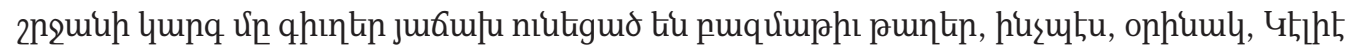

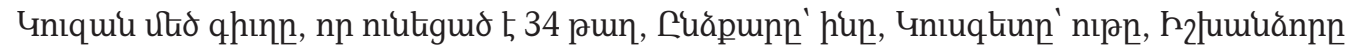

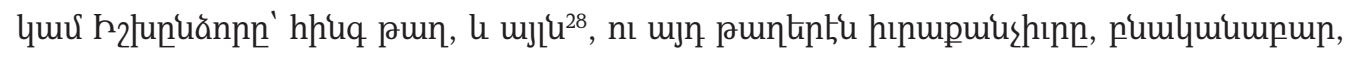

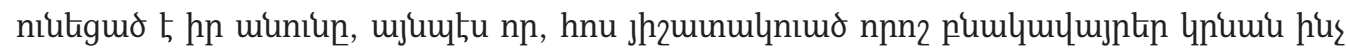

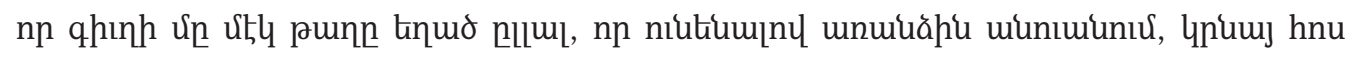

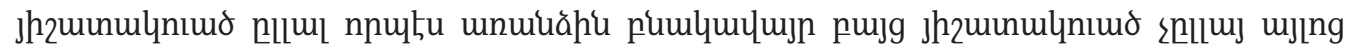
Uoun:

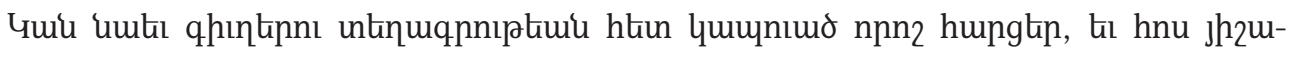

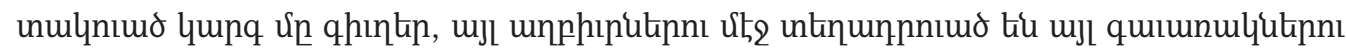
Uit, 2 :

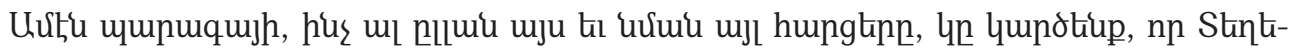

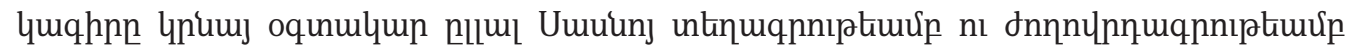

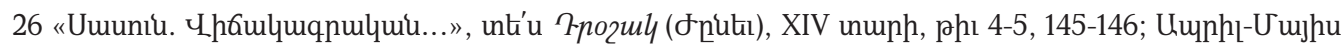

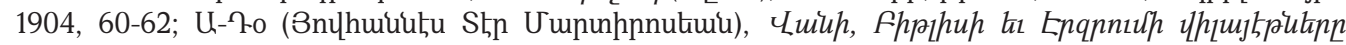

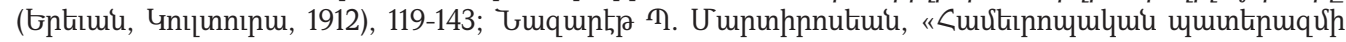

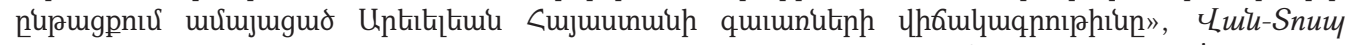

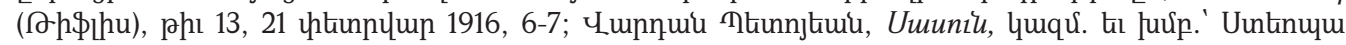

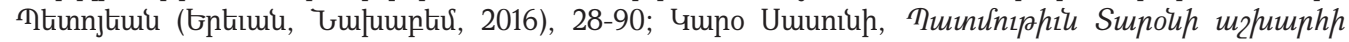

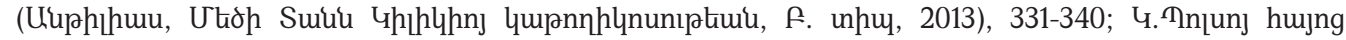

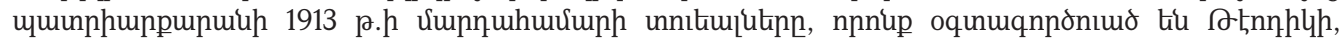

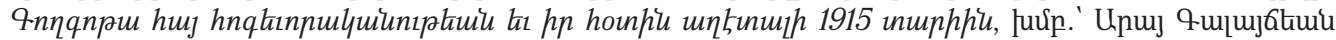

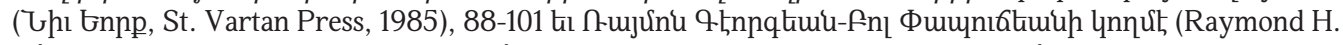
Kévorkian, Paul B. Paboudjian Les Arméniens dans l'empire Ottoman a la veille du génocide (Фunpq, ARHIS,

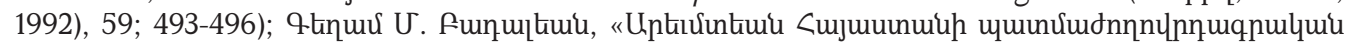

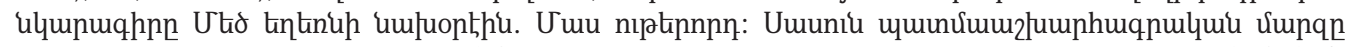

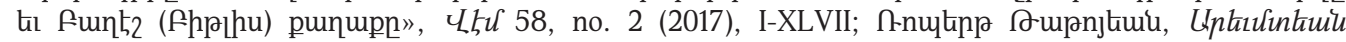

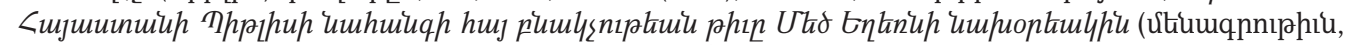

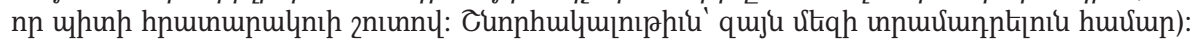

27 Thinnjtuiu, Umuniu, 66:

28 Thunnjtui, Umuniน, 28, 80, 66, 75: 


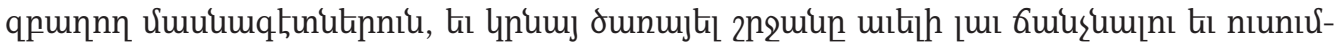
uwuhpt]ns w2łumunuiphi:

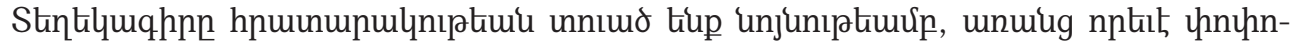

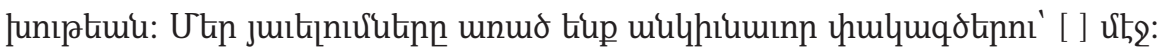

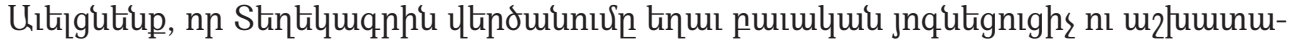

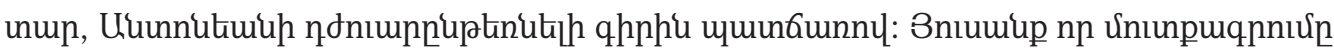
nnur nıluup wuußuml nı wuptiph:

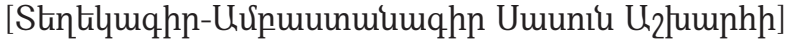

Uuuniu'

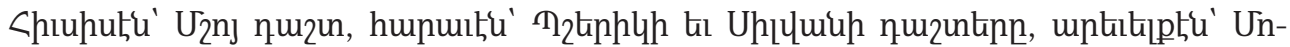

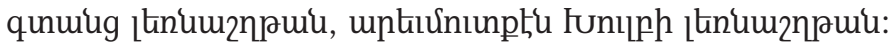

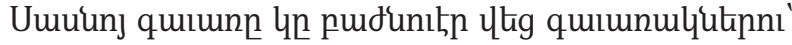

1. Sujunphly

2. fniuuiup

3. Cupup-Uunupnil

4. Uniuqtion

5. Anumiztu-tunı

6. Hupuip

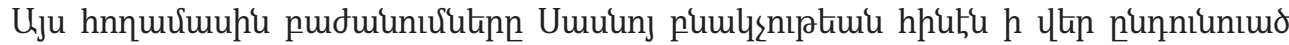

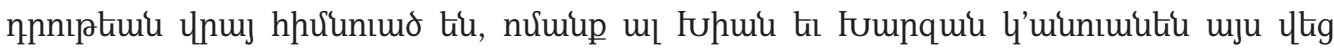
quilunitinn:

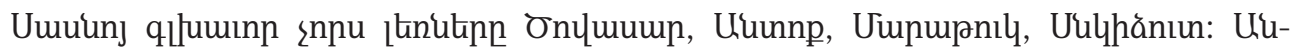

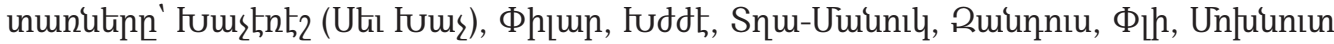

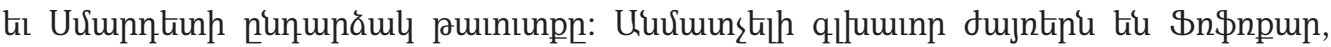

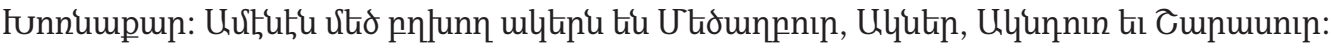

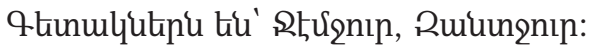

Uwuing Uounuinp wighulbu.

U. h2luwiumg dnnny:

f. Jlinng dnnnu:

१. คuulysug puqưugniu:

Ћ. Uuuung phipuntip:

৮. Uuuniughutipn qtuptip:

२. Uuuniughitipnı untnulquiu qpunnıx:

上. Uuuniughutipn ulumuqhnn:

ᄃ. 1894-96 pniuluuutinn:

ค. 1914-16 pnimumulutpn:

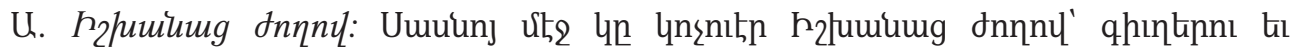




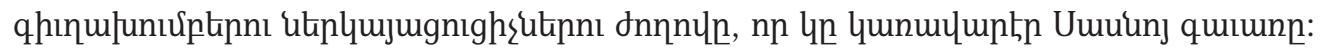

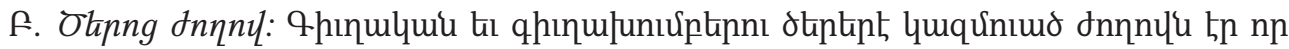

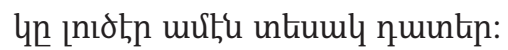

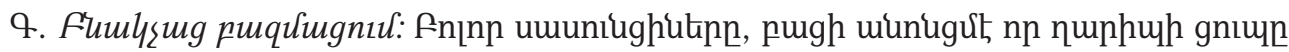

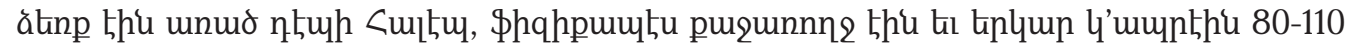

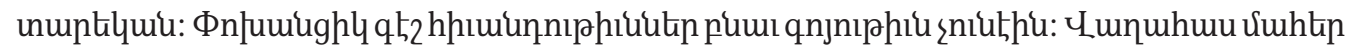

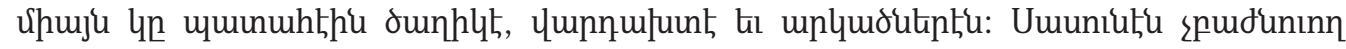

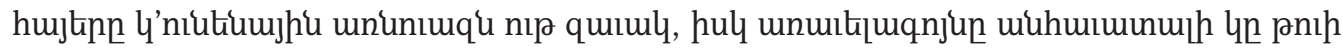

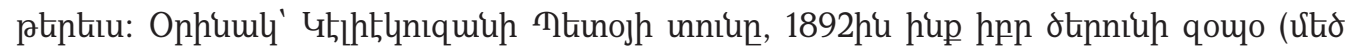

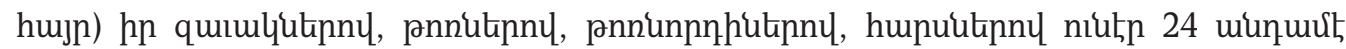

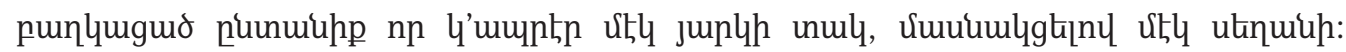

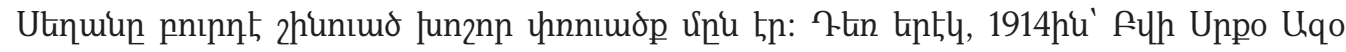

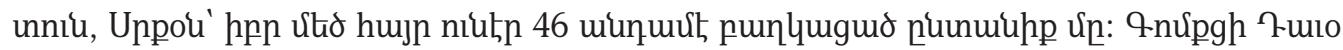

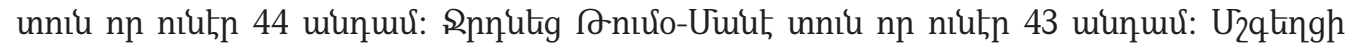

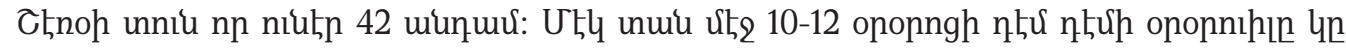
untuunitn:

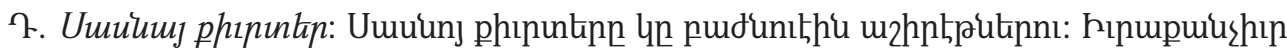

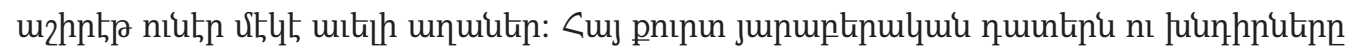

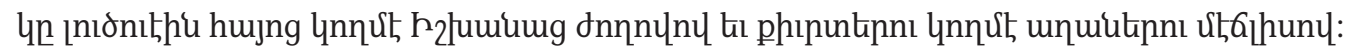

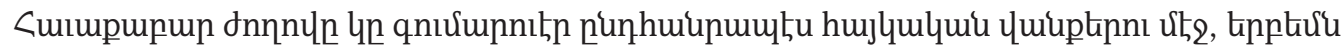

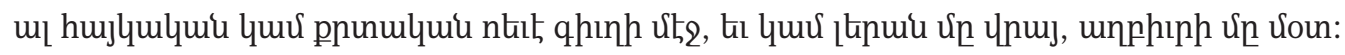

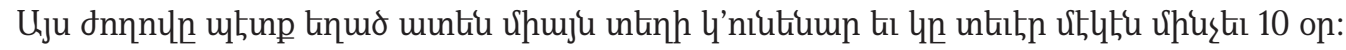

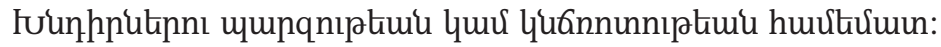

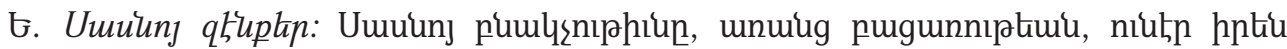

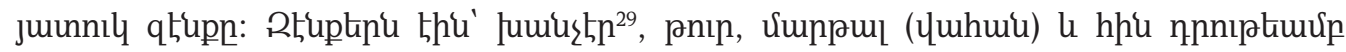

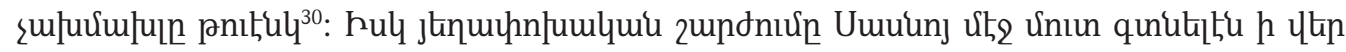

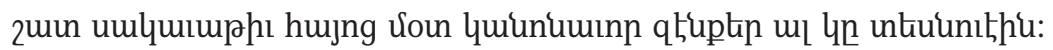

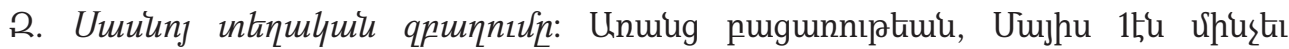

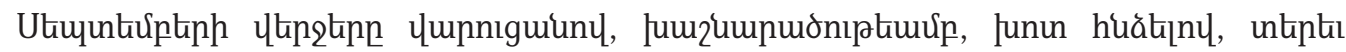

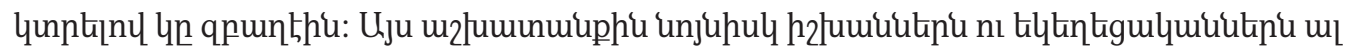

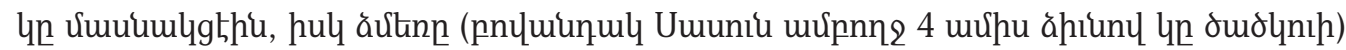

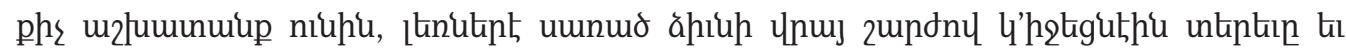

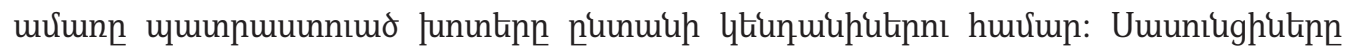

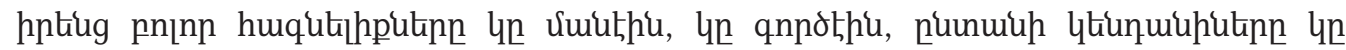

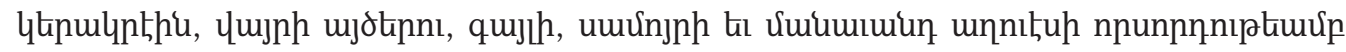

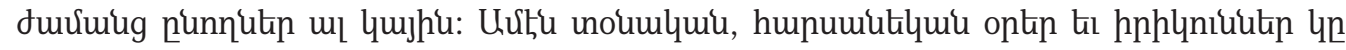

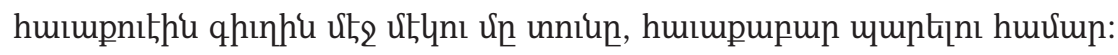

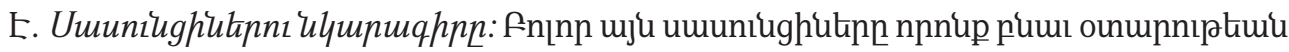

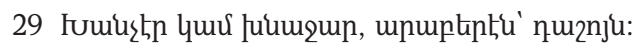

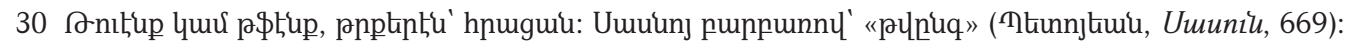




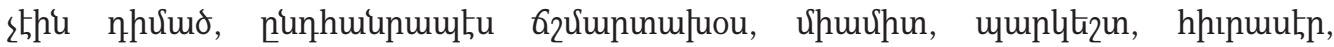
uzlumunuuth ki lnoumukn thi:

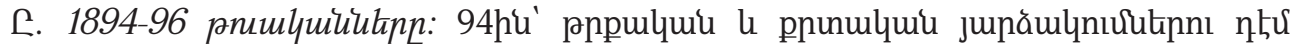

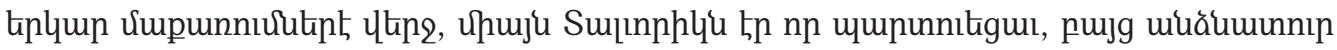

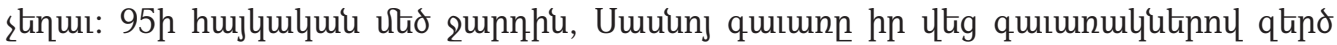

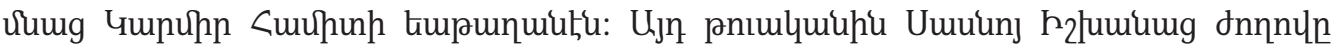

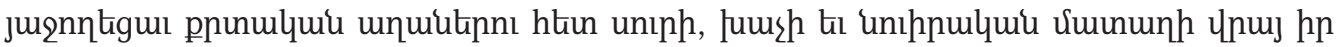

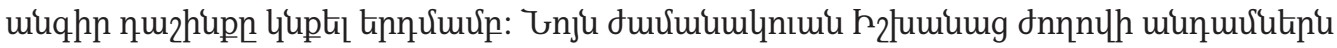
thi'

Thinulugh ₹ukou

Uppough Upuup unfoi

fưănngh Ghinuou

U2qtingh Ununlyh đtnou

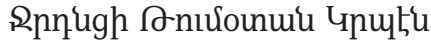

qnúpgh 4tрuщt Unkihuu

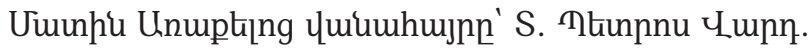

Unhthui પunn.

Sulınnhlgh <uưqü

fnınпо quuumu

enntigh S. qupnhth Puhwumu

epınu unuutphu thu'

ctlyounum Solnnip

Uwhunnunt fumlhl

qninuigh Uunou

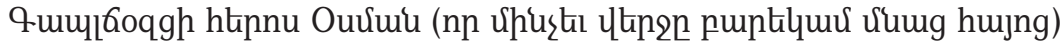

Uniuth Cuumut 2tılh

Rthritulh Cuuth Tnuhhr:

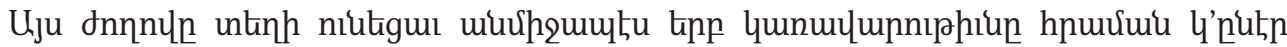

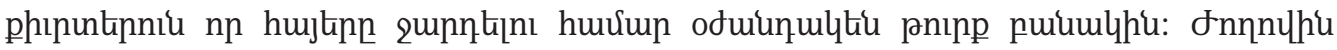

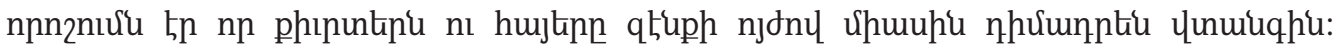

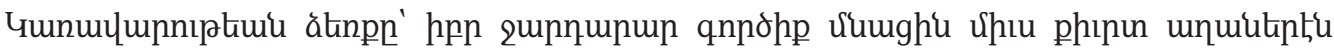

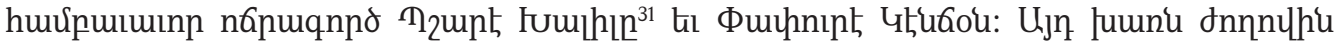

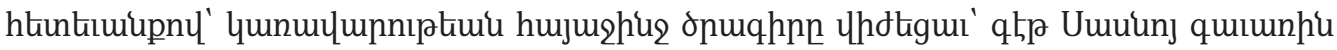
Ut,2:

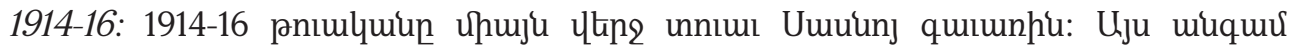

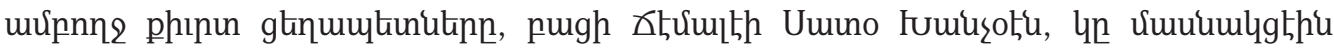

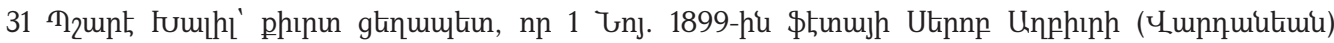

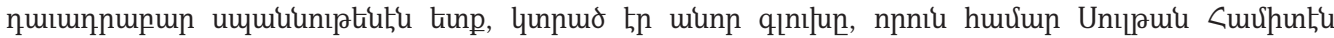

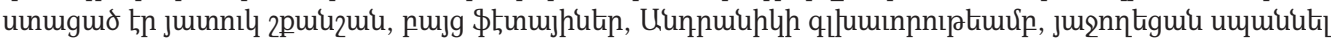
qhup nı hptiug lunqhi yunntil hn qinılun: 


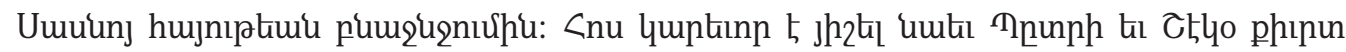

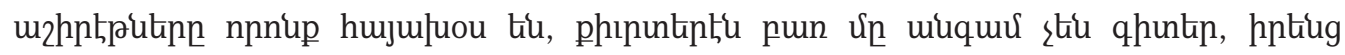

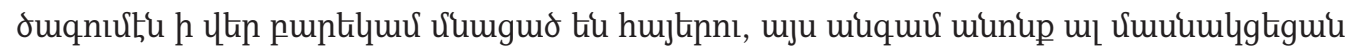
qupntinniu:

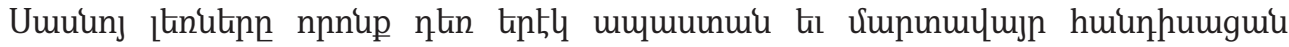

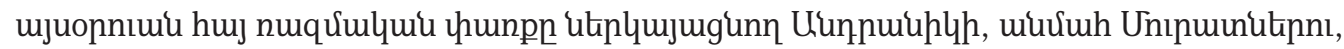

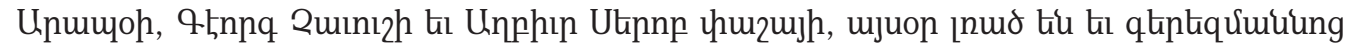

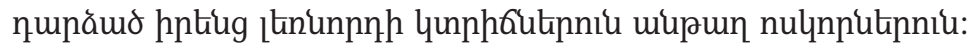

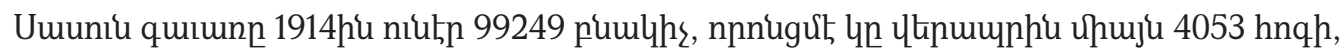

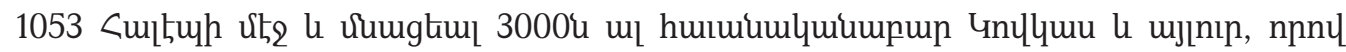
l'nıutuuuup 95196 wuăh unnnıuun:

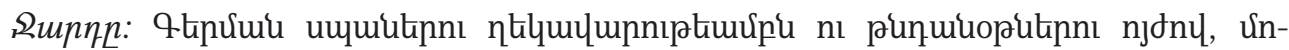

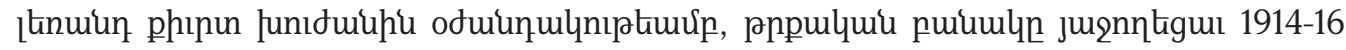

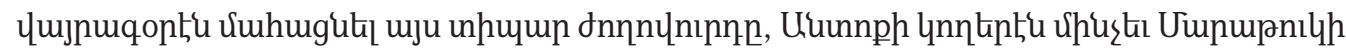
junntinn:

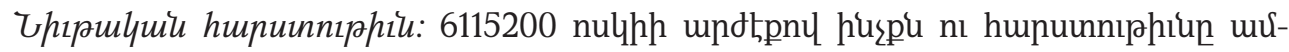

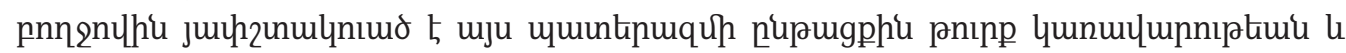
phinu Junıduuhu lnnuls:

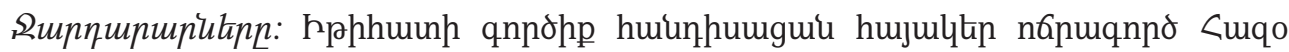

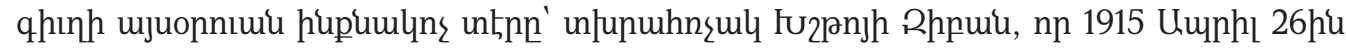

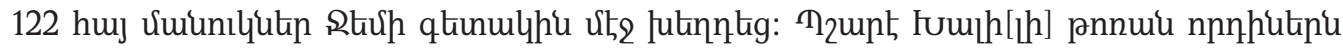

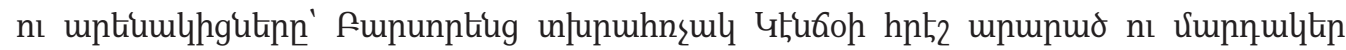

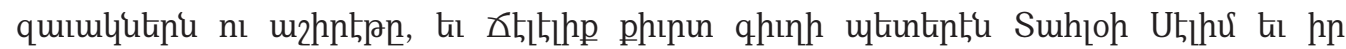

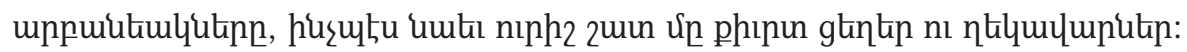

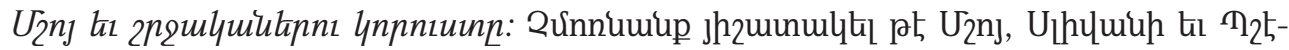

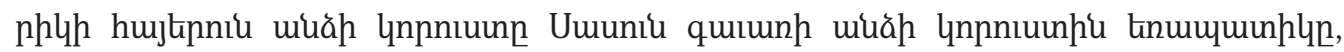

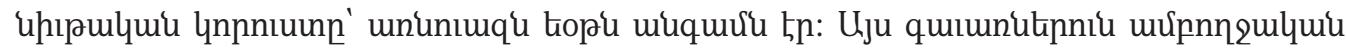

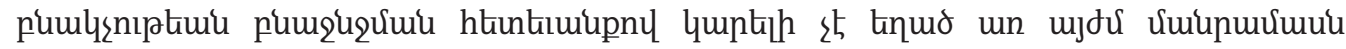
untinthniphiu hưumul:

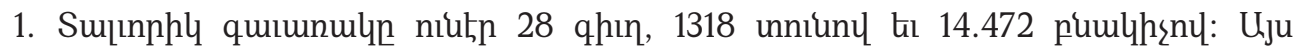

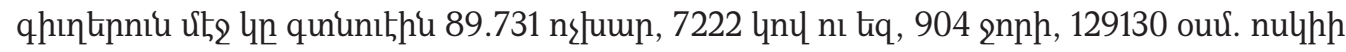

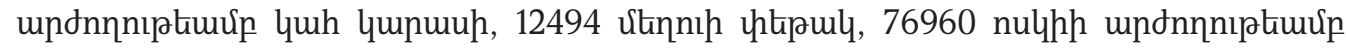
ujqhutip nı umununtqutin:

\begin{tabular}{|c|c|c|c|}
\hline & & Snıu & pumulh \\
\hline 1 & Фnıpu & 12 & 126 \\
\hline
\end{tabular}




\begin{tabular}{|c|c|c|c|}
\hline 2 & Cupuiuup & 6 & 68 \\
\hline 3 & Anımltup & 18 & 205 \\
\hline 4 & Cnuuniun & 8 & 72 \\
\hline 5 & Cupunp & 19 & 363 \\
\hline 6 & Ltiphu 9kn & 40 & 603 \\
\hline 7 & Uunquip & 42 & 705 \\
\hline 8 & Fulhnulhun & 7 & 82 \\
\hline 9 & Unph & 52 & 705 \\
\hline 10 & fopulup & 5 & 40 \\
\hline 11 & Clnntiup & 22 & 193 \\
\hline 12 & Gnlumun & 16 & 138 \\
\hline 13 & Chphup & 120 & 1340 \\
\hline 14 & Fundtouluup & 8 & 92 \\
\hline 15 & Ghıht 4nıqui & 248 & 2030 \\
\hline 16 & Unqhy & 40 & 304 \\
\hline 17 & 9nu & 152 & 1560 \\
\hline 18 & Чunर्uा & 141 & 1600 \\
\hline 19 & Cbunp & 102 & 807 \\
\hline 20 & Utưul & 70 & 938 \\
\hline 21 & hnguip & 63 & 800 \\
\hline 22 & 4thlht ก-52 & 13 & 87 \\
\hline 23 & Dluply & 10 & 37 \\
\hline 24 & Onı2umultipl & 15 & 200 \\
\hline 25 & Cunlunnp & 30 & 480 \\
\hline 26 & Utulkn & 26 & 370 \\
\hline 27 & Uuqnt & 10 & 227 \\
\hline 28 & Utunnu2zu & 23 & 300 \\
\hline
\end{tabular}

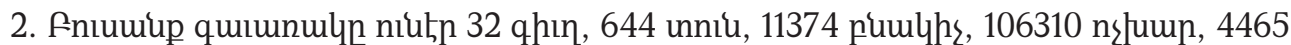

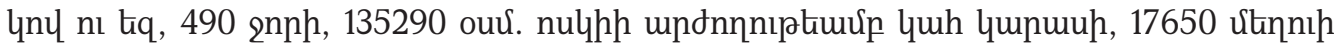

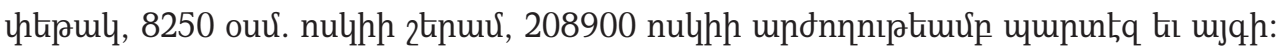

\begin{tabular}{|c|c|c|c|}
\hline 1 & 9nulin & 14 & 306 \\
\hline 2 & Pnunưưup & 18 & 410 \\
\hline 3 & Snuitin & 6 & 60 \\
\hline 4 & Cuilunup & 13 & 160 \\
\hline 5 & enunцuup & 8 & 45 \\
\hline 6 & Uuăunlki|h & 6 & 67 \\
\hline
\end{tabular}




\begin{tabular}{|c|c|c|c|}
\hline 7 & Phupulu & 13 & 84 \\
\hline 8 & Pupuip & 14 & 350 \\
\hline 9 & Rnnuhp & 46 & 810 \\
\hline 10 & fuh & 32 & 430 \\
\hline 11 & qnup & 42 & 670 \\
\hline 12 & Uqnuiu & 6 & 67 \\
\hline 13 & uptiōnn & 15 & 97 \\
\hline 14 & $\Phi_{2 \text { niun }}$ & 22 & 380 \\
\hline 15 & Rku & 12 & 160 \\
\hline 16 & T-uphnn & 28 & 530 \\
\hline 17 & Tlillotup & 13 & 290 \\
\hline 18 & fulqunhp & 5 & 60 \\
\hline 19 & Punoup & 8 & 90 \\
\hline 20 & $U_{2 q} \mathrm{kn}$ & 50 & 1100 \\
\hline 21 & Iưănnhp & 42 & 890 \\
\hline 22 & Thuunniu & 6 & 120 \\
\hline 23 & Aupnıp & 23 & 340 \\
\hline 24 & fqniwup & 12 & 180 \\
\hline 25 & Gonulţu & 14 & 270 \\
\hline 26 & Găpun & 8 & 130 \\
\hline 27 & २mduquunphl & 26 & 470 \\
\hline 28 & Uupupu & 16 & 200 \\
\hline 29 & Puqntiup & 34 & 720 \\
\hline 30 & Upptiup & 46 & 960 \\
\hline 31 & fuuunh & 35 & 870 \\
\hline 32 & Ulnkiuiu Uuqnum & 6 & 60 \\
\hline
\end{tabular}

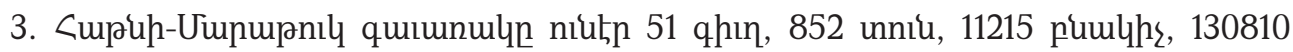

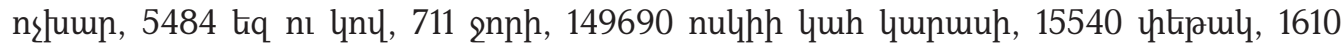
nulhh 2 tipuu, 163620 nulhh wnun nı umununtq:

\begin{tabular}{|c|c|c|c|}
\hline 1 & Uuulhl & 13 & 170 \\
\hline 2 & Thцuu & 14 & 180 \\
\hline 3 & Unp 4tin & 25 & 290 \\
\hline 4 & quum foq & 44 & 580 \\
\hline 5 & funpuuर & 11 & 190 \\
\hline 6 & Guunopu & 24 & 370 \\
\hline 7 & <nu & 20 & 350 \\
\hline
\end{tabular}




\begin{tabular}{|c|c|c|c|}
\hline 8 & Unıptuniu & 25 & 400 \\
\hline 9 & 4nn & 18 & 150 \\
\hline 10 & T)uunnúniun & 26 & 450 \\
\hline 11 & fumpltn & 10 & 180 \\
\hline 12 & Unnny & 15 & 290 \\
\hline 13 & Lunun & 10 & 200 \\
\hline 14 & Cnniun & 16 & 220 \\
\hline 15 & qnúpp & 17 & 250 \\
\hline 16 & पozml & 19 & 210 \\
\hline 17 & Фhn2tup & 30 & 500 \\
\hline 18 & Untqntu & 8 & 95 \\
\hline 19 & Dlup & 10 & 110 \\
\hline 20 & 2npunph & 5 & 60 \\
\hline 21 & ५unvuluip & 12 & 125 \\
\hline 22 & hnguiup & 5 & 50 \\
\hline 23 & Gnınunlwuip & 10 & 150 \\
\hline 24 & Onåhq & 8 & 120 \\
\hline 25 & qoúnuntp & 6 & 98 \\
\hline 26 & ᄀ-uׁnănn & 7 & 90 \\
\hline 27 & Uqnıh & 8 & 54 \\
\hline 28 & Tpuuqunniu & 4 & 60 \\
\hline 29 & Cumy2unnı & 5 & 100 \\
\hline 30 & Cluunhl & 13 & 100 \\
\hline 31 & Punphl & 8 & 70 \\
\hline 32 & Cunqnip & 6 & 60 \\
\hline 33 & Purp $_{2}$ tiup & 40 & 170 \\
\hline 34 & Uuntiup & 18 & 130 \\
\hline 35 & Unnumup & 11 & 130 \\
\hline 36 & fumuluup & 5 & 60 \\
\hline 37 & unpnkin & 28 & 290 \\
\hline 38 & Fumunph & 19 & 180 \\
\hline 39 & LLunnniung & 8 & 100 \\
\hline 40 & Sulkinp & 29 & 570 \\
\hline 41 & Punlhg & 6 & 90 \\
\hline 42 & Unlunng & 9 & 100 \\
\hline 43 & Ununnh & 12 & 130 \\
\hline 44 & <nălumup & 18 & 300 \\
\hline
\end{tabular}




\begin{tabular}{|c|c|c|c|}
\hline 45 & Qthumu & 8 & 95 \\
\hline 46 & fpunuiup & 10 & 180 \\
\hline 47 & Guilyuntiup & 13 & 208 \\
\hline 48 & Chnnun & 18 & 300 \\
\hline 49 & Unðnıhp & 80 & 850 \\
\hline 50 & fumu & 42 & 600 \\
\hline 51 & Thluultup & 26 & 380 \\
\hline
\end{tabular}

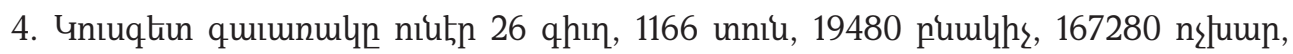

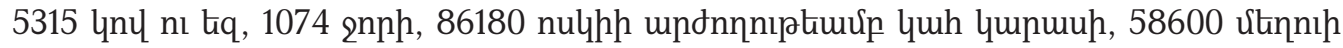

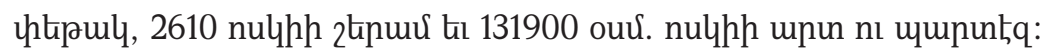

\begin{tabular}{|c|c|c|c|}
\hline 1 & Pundtin & 20 & 280 \\
\hline 2 & Onuqh2 & 26 & 300 \\
\hline 3 & Anulip & 17 & 270 \\
\hline 4 & Gnunndtip & 23 & 420 \\
\hline 5 & Gtipphu Unıuqtin & 200 & 3000 \\
\hline 6 & Uh24uinum & 34 & 600 \\
\hline 7 & 2onniun & 6 & 75 \\
\hline 8 & Uuh & 30 & 570 \\
\hline 9 & flup & 10 & 85 \\
\hline 10 & 2र्um & 25 & 160 \\
\hline 11 & Snltiun & 16 & 180 \\
\hline 12 & Unuiun & 150 & 2500 \\
\hline 13 & unpuwu & 205 & 3050 \\
\hline 14 & Unцh & 50 & 800 \\
\hline 15 & Unn2tu & 8 & 150 \\
\hline 16 & fnlưnun & 22 & 460 \\
\hline 17 & Ununquiu & 88 & 1850 \\
\hline 18 & Uhs & 40 & 870 \\
\hline 19 & Uupuluiun & 60 & 1400 \\
\hline 20 & Ullnuin & 16 & 380 \\
\hline 21 & Gpunh & 26 & 560 \\
\hline 22 & ५t, & 8 & 150 \\
\hline 23 & पduip & 40 & 750 \\
\hline 24 & Rnunnip & 22 & 230 \\
\hline 25 & 9nnеnip & 16 & 180 \\
\hline 26 & Ununptip & 18 & 210 \\
\hline
\end{tabular}




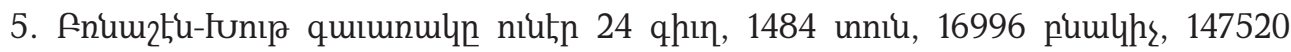

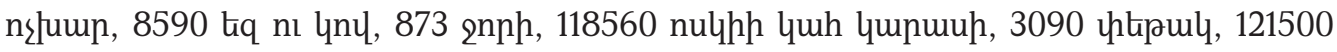
nulhh unun nı ưununtq:

\begin{tabular}{|c|c|c|c|}
\hline 1 & $\mathrm{O}_{2}$ niun & 15 & 170 \\
\hline 2 & fintuh & 20 & 242 \\
\hline 3 & Cunluuănn & 50 & 574 \\
\hline 4 & ¿ulnıqtil & 48 & 510 \\
\hline 5 & Suzunumbu & 35 & 370 \\
\hline 6 & Unnıp & 42 & 480 \\
\hline 7 & Dunnıh & 70 & 810 \\
\hline 8 & م-unuumup & 164 & 1700 \\
\hline 9 & Dunnt & 32 & 300 \\
\hline 10 & Lnnnuănn & 14 & 170 \\
\hline 11 & પunh Cuhuun & 18 & 200 \\
\hline 12 & unjup & 23 & 260 \\
\hline 13 & Aưnuănn & 95 & 810 \\
\hline 14 & Fhønup & 79 & 800 \\
\hline 15 & Uqpum & 120 & 1120 \\
\hline 16 & 4nınuly & 26 & 310 \\
\hline 17 & othu & 225 & 2700 \\
\hline 18 & đupuun & 160 & 2510 \\
\hline 19 & Gulknunhu & 8 & 100 \\
\hline 20 & On2niun & 45 & 520 \\
\hline 21 & $\Phi_{2 n h l}$ & 40 & 690 \\
\hline 22 & Unर्umnu & 70 & 710 \\
\hline 23 & ก-шиши & 45 & 510 \\
\hline 24 & 4nnџnın & 40 & 430 \\
\hline
\end{tabular}

6. Iuhump quimnuly ln punlumump 42 qhint, 1743 unniu, 25710 pumlhs,

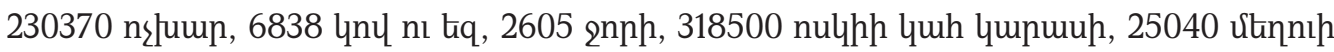

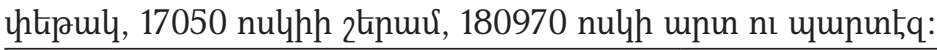

\begin{tabular}{|c|c|c|c|}
\hline 1 & Tthuưunu & 70 & 700 \\
\hline 2 & ઠnưunu & 46 & 450 \\
\hline 3 & unthun|uh & 18 & 250 \\
\hline 4 & untưnnt & 9 & 150 \\
\hline 5 & funlqu & 90 & 1800 \\
\hline 6 & Uunnuniu & 78 & 1200 \\
\hline
\end{tabular}




\begin{tabular}{|c|c|c|c|}
\hline 7 & Clunhu & 90 & 1600 \\
\hline 8 & Tদৈnर & 150 & 2500 \\
\hline 9 & ethnp & 37 & 800 \\
\hline 10 & Ununlniup & 40 & 850 \\
\hline 11 & Suntiutin & 50 & 950 \\
\hline 12 & xtoúlthunuahly & 5 & 70 \\
\hline 13 & $\Phi b_{22} \mathrm{~h}$ & 17 & 410 \\
\hline 14 & عulnıquuly & 30 & 720 \\
\hline 15 & Utıhun & 9 & 120 \\
\hline 16 & Unцuиц & 14 & 230 \\
\hline 17 & Tulnıtiup & 12 & 300 \\
\hline 18 & Uuunnılu & 25 & 570 \\
\hline 19 & Iunznp & 15 & 450 \\
\hline 20 & Uunlin & 94 & 1500 \\
\hline 21 & पnưuu & 20 & 250 \\
\hline 22 & Unumiun & 35 & 400 \\
\hline 23 & Fumjunhl & 45 & 500 \\
\hline 24 & Onıntly & 15 & 120 \\
\hline 25 & Shlth & 25 & 350 \\
\hline 26 & Guh2u & 50 & 400 \\
\hline 27 & Фuunın & 180 & 1850 \\
\hline 28 & ก-huulu & 60 & 650 \\
\hline 29 & runnik & 35 & 350 \\
\hline 30 & Guul & 50 & 700 \\
\hline 31 & Snıquilin & 15 & 200 \\
\hline 32 & бthuщnıщu & 7 & 60 \\
\hline 33 & h2luuănn & 82 & 1450 \\
\hline 34 & 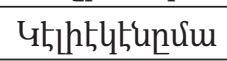 & 50 & 800 \\
\hline 35 & U.2luniu & 20 & 250 \\
\hline 36 & Ulnılu & 40 & 300 \\
\hline 37 & Unjuniuun & 80 & 1200 \\
\hline 38 & Unnu & 5 & 40 \\
\hline 39 & Suuăhly & 5 & 30 \\
\hline 40 & Uţnulh & 2 & 20 \\
\hline 41 & Cumpt & 8 & 50 \\
\hline 42 & Cunnut & 15 & 120 \\
\hline
\end{tabular}




\begin{tabular}{|c|c|c|c|c|c|c|c|c|c|c|}
\hline $\begin{array}{l}\text { 9uiu- } \\
\text { nulyutep }\end{array}$ & qhin & unniu & nsluwn & $\begin{array}{l}\text { tiq no } \\
\text { lnny }\end{array}$ & ¿nnh & $\begin{array}{l}\text { y u h } \\
\text { yunum- } \\
\text { up ouर. } \\
\text { nulh }\end{array}$ & puulyhs & $\begin{array}{l}\text { utunıl } \\
\text { utupuly }\end{array}$ & 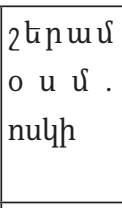 & $\begin{array}{l}\text { upun nt } \\
\text { uyup un t q } \\
\text { ouv. nulh }\end{array}$ \\
\hline Sujınphl & 28 & 1318 & 89731 & 7222 & 904 & 129130 & 14472 & 12492 & ---- & 76930 \\
\hline fnıuwiumg & 32 & 644 & 106310 & 4465 & 490 & 135090 & 11376 & 17650 & 8250 & 208900 \\
\hline $\begin{array}{l}\angle \mathrm{u} \text { p i h } \mathrm{p}- \\
\text { Uwnupnsl }\end{array}$ & 51 & 852 & 130810 & 5484 & 711 & 149690 & 11215 & 15540 & 1610 & 163620 \\
\hline uniuqtiun & 26 & 1166 & 167280 & 5315 & 1074 & 86180 & 19480 & 58600 & 2610 & 131900 \\
\hline $\begin{array}{l}\text { Anumertu- } \\
\text { funip }\end{array}$ & 24 & 1484 & 147520 & 8590 & 873 & 118560 & 16996 & 3090 & 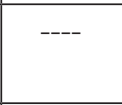 & 121500 \\
\hline IUhuip & 42 & 1743 & 230370 & 6838 & 2605 & 318500 & 25710 & 25040 & 17050 & 180970 \\
\hline qnıưup & 203 & 7207 & 872021 & 37914 & 6657 & 937150 & 99249 & 132412 & 29520 & 883820 \\
\hline
\end{tabular}

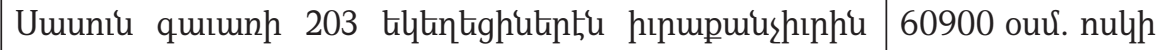
unpuquiu uiuoputipniu, qupntintuuknniu kı qnjphnniu undtpp 300 ouv. nulhţ

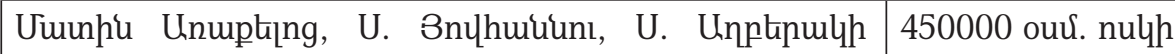
umuptipns unthpuluuu undtpp

\begin{tabular}{|c|c|}
\hline 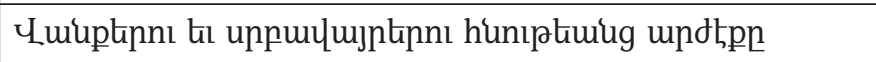 & 800000 ouv. nulh \\
\hline 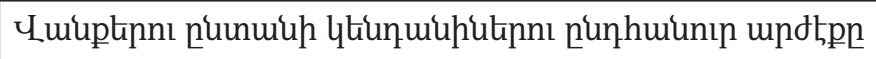 & 26000 ouv. nulh \\
\hline 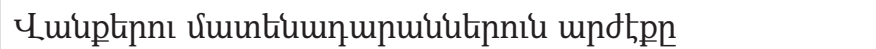 & 300 ouर.nulh \\
\hline Uuuinj quilunh qpunughtipns undtpp & 20800 ouर. nulh \\
\hline 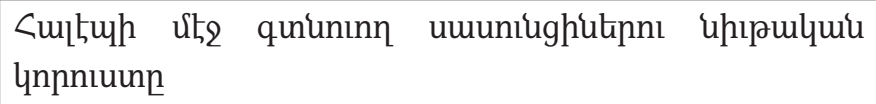 & 85000 ouv. nulh \\
\hline [Qnưup] & 1382100 ouv. nulh \\
\hline 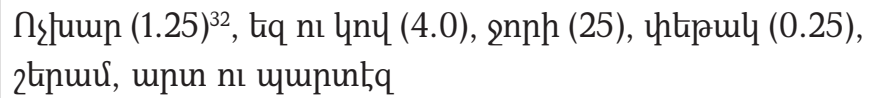 & 4733100 ouv. nulh \\
\hline [Qnıưup] & 6115200 our. nulh \\
\hline
\end{tabular}

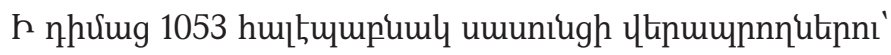
Uuuins Uhnıthuiu thuqopitip'

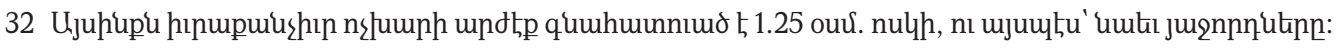


Ulynuns Phuj. Unıpuuntumu

Shqnuir Gntghum

unuu Gntghuiu

Uuunith Uupunpnnukuiu

Unyutu Uúpplumitumiu

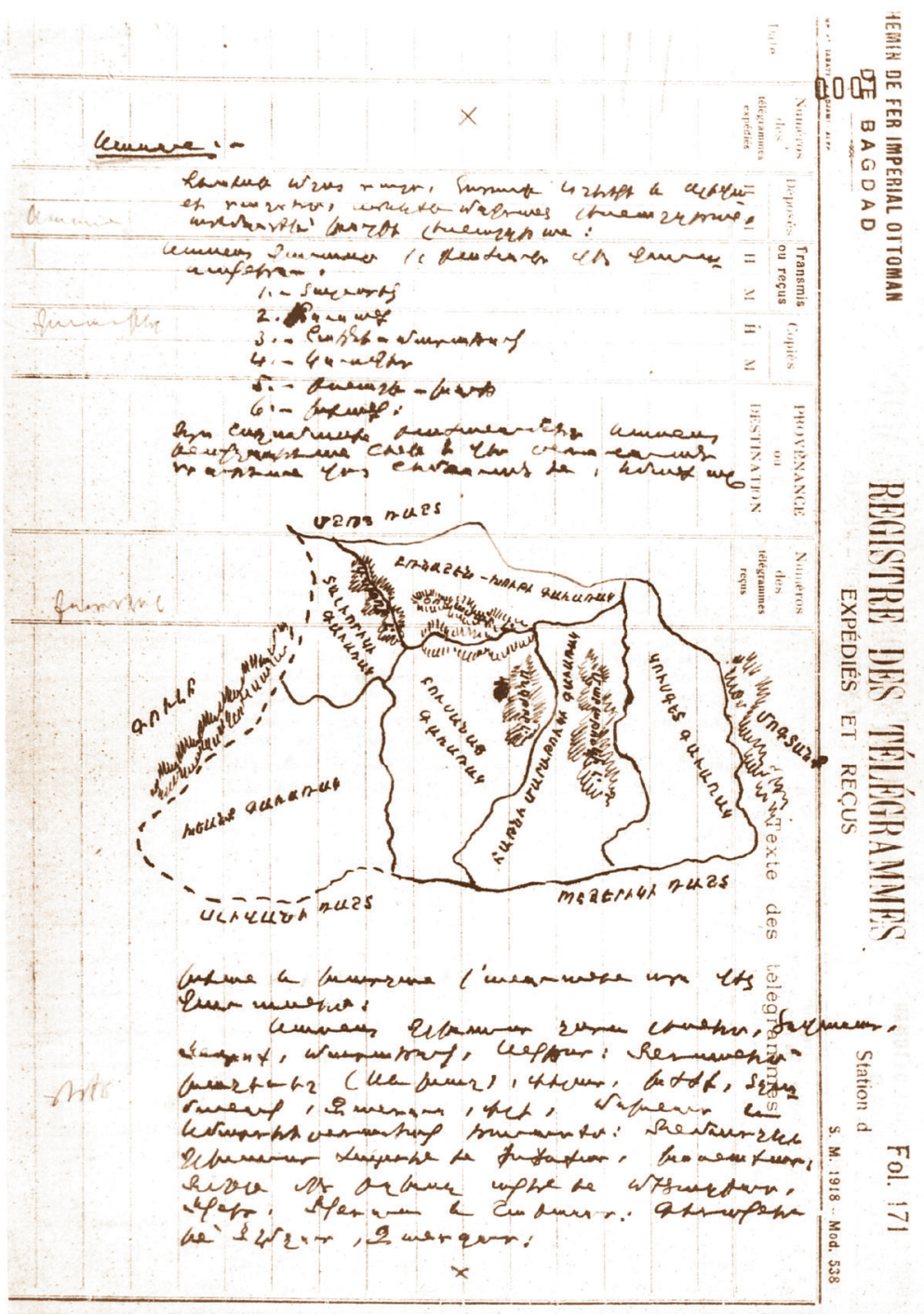

Uuuunj Stintlumqnhi unwehi ton 


\title{
THE INDICTMENT DOCUMENTS ON THE ARMENIAN GENOCIDE WRITTEN IN ALEPPO AND THE SASSOUN DOCUMENT (1919)
}

\author{
Mihran A. Minassian \\ Armenian Genocide Museum-Institute Foundation, Armenia
}

\section{SUMMARY}

The article is divided into two parts. The first part covers the development of indictment documents by patriotic unions or fractions of Aleppo in order to submit them to the Paris Peace Conference in 1919, each of which was a summary of the history of the Armenian massacres of a specific region. The overall list of the covered material and the content of each document are also outlined. It is interesting that the documents dedicate large sections for listing the names of the Turkish perpetrators of each region and the material losses suffered by the Armenians.

The second part of the article includes the indictment document of Sassoun district, which contains general geographical information and important details about the social life of the Armenians of Sassoun, i.e. meetings of principals and elders, Armenian-Kurdish relations, the situation of the Armenians of Sassoun in 1894-1896 and 1914-1916, and a brief list of the perpetrators of the massacres. The second part of the document covers the village lists and censuses of the six sub-districts of Sassoun - Dalvorig, Pusank, Hatni-Maratug, Gusked, Pernashen-Khut and Khiank, where 203 villages are mentioned with the numbers of their Armenian population and other details.

Key words: Armeian Genocide, Aleppo, Inter-Provincial Patriotic Union, Aram Andonean, prof. Haygazoun Aramean, Karapet Gabikean, Armenian Genocide Indictment Documents, Western Armenia, Cilicia, Asia Minor, Sassoun district, Versailles Peace Conference.

\section{СОЗДАННЫЕ В АЛЕППО ОБВИНИТЕЛЬНЫЕ СПРАВОЧНИКИ ГЕНОЦИДА АРМЯН И СПРАВОЧНИК САСУНА (1919 Г.)}

\author{
Мигран А. Минасян \\ Фонд “Музей-институт Геноцида армян,” Армения
}

\section{РЕЗЮМЕ}

Статья разделена на две части. Первая часть посвящена созданию землячествами или организациями Алеппо обвинительных справочников для предоставления Парижской мирной конференции в 1919 году, каждый из которых содержал краткую историю резни армян в отдельных районах. В общих чертах представлены содержание и список освещенных тем 
каждого справочника. Примечательно, что в каждом справочнике большое место отведено спискам турецких преступников и материальным потерям армян.

Во второй части статьи представлен справочник провинции Сасун, в котором содержатся общие географические сведения и важные данные об общественной жизни Сасуна: княжеский (h2lumuug) совет и совет старейшин, армяно-курдские отношения, положение армян Сасуна в 1894-1896 и 1914-1916 годах и краткий список погромщиков. Здесь же представлены список деревень и перепись населения шести округов Сасуна - Талворик, Бусанк, Атни-Маратук, Кусгет, Брнашен-Хут и Хиат. В общем и целом отмечены 203 деревни, для каждой из них отмечено число домов и представителей армянского населения и т.д.

Ключевые слова: Геноцид армян, Алеппо, межпровинциальное землячество, обвинительные справочники Геноцида армян, Западная Армения, Киликия, Малая Азия, область Сасуна, Версальская мирная конференция.

\section{REFERENCES}

Cultuph Uqqujhi unuginnnupuuh uplupı [Archives of the Aleppo National Prelacy]; $<$ <uj 2uju [Armenian Voice]. Aleppo, 1918;

чшiи-Snuw [Van-Dosp], no. 13, 21, Tiflis, 1916, 6-7;

«Uuunil. บhfulquqnulumu...» [Sasoun: Statistics...]. Rpozml [Droshag]. Geneva, 1904;

A-Do (Der-Mardirosian, Hovhannes). પuuh, fhplhup l Enqnnulp uhjujtpluthn [ The vilayets of Van, Bitlis and Erzurum]. Yerevan: Kultura, 1912;

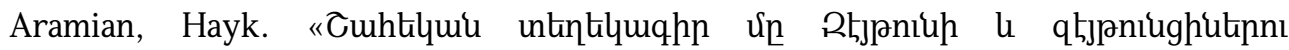
nnpkpqniptuiu Uuupu», [A Beneficial Bulletin about the Tragedy of Zeytun and the People of Zeytun]. Memorial Book of the Armenian Martyrdom (1915-1965), III ed., Beirut: Zart'onq, 1987, 850-854;

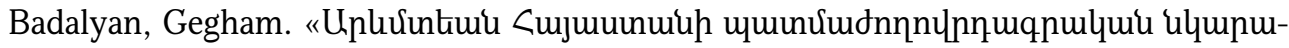

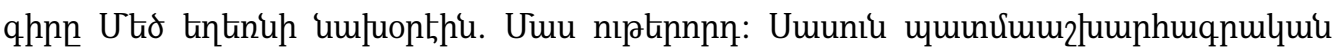
Uunqn lu funt2 (Ahplhu) punupp» [Historical and Demographic Image of Western Armenia on the Eve of the Armenian Genocide: Part 8. Historical-geographical District of Sasun and the Town Baghesh (Bitlis)]. VEM Pan-Armenian Journal 2 no. 58 (2017): I- XLVII;

Chizméchean, Manuk. Kumpptapn tus hn quiuliktnn [Kharberd and its offsprings]. Frezno-California, 1955;

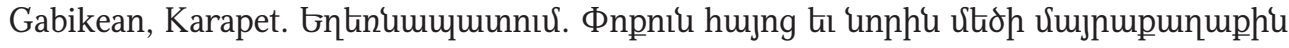
Uthuuunhn] [Yeghernapatum (history of genocide) of Armenia Minor and its Great Capital Sebastia]. Boston: Hayreniq, 1924;

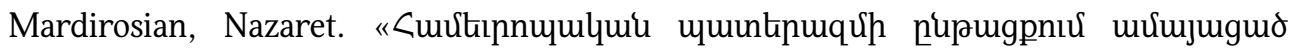

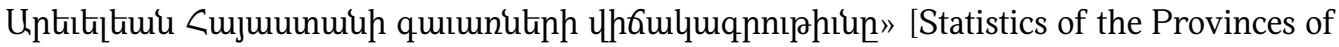


Eastern Armenia deserted during the Pan-European War]. Van Tosp (Tiflis), 12 Feb. 1916;

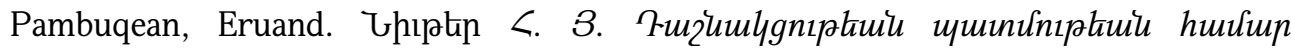
[Materials for the History of A.R. Federation. vol. XII]. Beirut: Hamazkayin Vahe Setian, 2016;

Petoyan, Vartan. Uuuniน [Sassoun]. Yerevan: Nakhapem, 2016;

Sasouni, Karo. Tuununıphik Sunouh wzhuuphh [History of Daron]. Antelias: House of the Armenian Catholicosate of Cilicia, 2013;

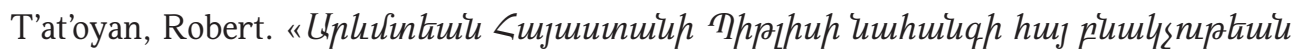

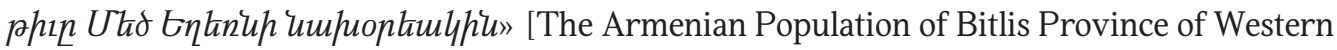
Armenia on the Eve of the Armenian Genocide] (forthcoming);

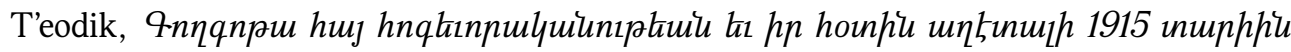
[Golgotha of the Armenian Clergy and its Flock in Catastrophic 1915]. New York: St. Vartan Press, 1985;

Vartan, Levon. «Uúpuuunuuuqhp-Stntiluuqhnutp» [Accusatory-Reports]. Haigazian Armenological Review XV (1995): 497-553.

\section{<tinhiuulh uruuhi \\ About the Author \\ Об авторе}

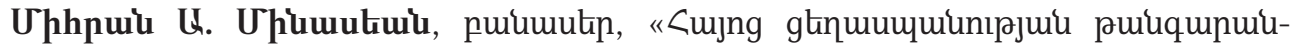

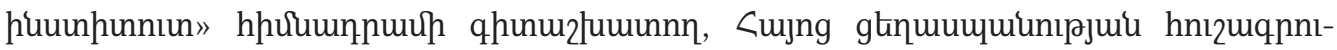

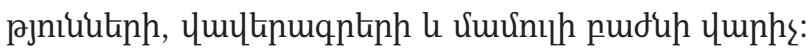

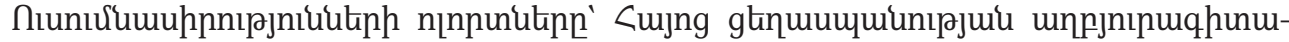

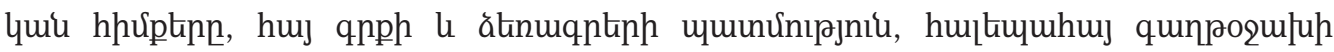

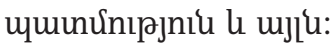

El. uhnuunh huugt’ minassian.mihran@genocide-museum.am

Mihran A. Minassian, Philologist, Head of the Department of the Armenian Genocide Memoires, Documents and Press, Armenian Genocide Museum-Institute Foundation.

Research fields - sources of the Armenian Genocide studies, history of the Armenian book and manuscripts, history of Aleppo-Armenian colonies.

E-mail: minassian.mihran@genocide-museum.am

Мигран А. Минасян, филолог, научный сотрудник, заведующий отделом Фонда “Музей-институт Геноцида армян."

Область исследований - источниковедение Геноцида армян, история армянской книги и рукописей, история армянской общины Алеппо и т. д.

Эл. почта: minassian.mihran@genocide-museum.am 